\title{
DOS VERSIONES SOBRE EL FENÓMENO JURÍDICO
}

\author{
Two versions of the legal phenomenon
}

Esteban Pereira Fredes*

\begin{abstract}
Resumen: Se examinan dos comprensiones sobre el fenómeno jurídico: una premoderna y otra moderna. A partir de la reflexión estética sobre el devenir pictórico, se presentan los postulados de identificación de ambas perspectivas, evaluando en forma crítica la pertinencia de reconocer la ruptura ocurrida en el ámbito estético en los asuntos jurídicos. Se sugiere el valor epistémico de la distinción en teoría jurídica analítica, pero se formulan algunas dificultades que enfrentaría su aplicación en discusiones de la filosofía del derecho privado contemporánea.
\end{abstract}

Palabras Clave: Fenómeno jurídico - estética - premodernidad - modernidad - teoría jurídica analítica - filosofía del derecho privado.

\begin{abstract}
The article examines two understandings of the legal phenomenon: a premodern one and a modern one. From the aesthetic reflection on the becoming pictorial, the postulates that identify both perspectives are presented, critically evaluating the appropriateness of recognizing the rupture occurred in the aesthetic realm in legal matters. It is suggested that the distinction in analytical legal theory has an epistemic value, but it is argued that there are some difficulties of implementation in the discussions of the contemporary philosophy of private law.
\end{abstract}

Keywords: Legal phenomenon - aesthetic - pre-modernity - modernity - analytical legal theory - philosophy of private law.

\section{Desde la ruptura sensible a la fractura jurídica}

El tránsito desde consideraciones estéticas hacia el escenario jurídico ofrece un cúmulo de dificultades, generadas a partir de la aparente distancia entre ambas parcelas del conocimiento. Una estrategia para intentar sortear tales vallas radica en presentar una diferenciación esgrimida en los estudios estéticos, y que cobra cada vez mayor relevancia en la organización de las concepciones acerca de lo jurídico. El contraste entre una perspectiva premoderna y otra moderna sobre la pintura acarreó gruesas contribuciones para la reflexión sobre lo bello, pero su

\footnotetext{
* Profesor Instructor, Facultad de Derecho, Universidad Adolfo Ibáñez. Dirección postal Diagonal Las Torres N²640, Peñalolén, Santiago, Chile. Correo electrónico: esteban.pereira@uai.cl.

Agradezco el agudo examen y las sugerencias formuladas por ambos árbitros anónimos de esta publicación. De igual modo, a Alberto Pino Emhart, Ernesto Riffo Elgueta y Héctor Morales Zúniga, por sus valiosos comentarios. Y, finalmente, a Isabel Arriagada Gajewski, por su incondicional apoyo para que esta publicación se materializare.
}

Este artículo fue recibido el 27 de septiembre de 2013, siendo aprobada su publicación el 8 de diciembre de 2014. 
rendimiento en los asuntos jurídicos constituye una cuestión no exenta de tensiones. La transparencia de esta distinción conceptual en el arte pudiere no comunicarse en el campo del derecho, donde efectivamente conviven diversas comprensiones sobre el fenómeno jurídico, pero no siempre resulta cristalino por cual de ellas es razonable adjudicar. Comenzaremos con las reflexiones sensibles y de ahí evaluaremos su pertinencia en las preocupaciones de la teoría del derecho.

La reflexión estética abrazó para propósitos metodológicos la distinción entre premodernidad y modernidad en el ámbito del conocimiento sensible de la pintura, rescatando sus amplias repercusiones en otras disciplinas artísticas. Charles Baudelaire articuló una sugerente taxonomía entre autores que habrían encarnado un prisma premoderno frente a otros que sostendrían un talante moderno bajo el devenir pictórico. Situó a pintores ilustres como Paul Cézanne, Edgar Degas, Edouard Manet y Eugène Delacroix en el paradigma moderno. Y, en tanto, identificó al francés Dominique Ingres como una expresión incontrovertible de lo premoderno en la pintura. Desde esta aproximación preliminar se devela que tras el marco teórico propuesto por Baudelaire no subyacen, en estricto rigor, criterios cronológicos. Si Ingres, frecuentemente asociado al movimiento neoclásico, que desarrolló buena parte de su obra durante el siglo XIX es ubicado en la esfera premoderna, se sigue que el sentido de la demarcación radica en la comprensión que sobre la pintura dicho autor tenía, sin detenerse en el contexto espacio-temporal desde donde formula su planteamiento.

Al evaluar los valores que se encuentran en juego en cada vertiente, logramos transparentar la disputa en el ámbito pictórico. Mientras los términos de necesidad, inmutabilidad, corrección, perfección y rigor de lo clásico están asociados a lo premoderno, el traslado hacia lo contingente y nociones como transitorio, fugitivo y artificial otorgan señales de lo moderno en la pintura. De ahí que Ingres sea ubicado bajo una comprensión teórica a la cual históricamente él no pudo haber pertenecido. En cuadros como La gran odalisca y su Gran bañista se plasma la belleza femenina mediante contornos bien definidos y contrastes de luces que iluminan a la modelo de turno. Por medio de figuras delicadas y hombros que se extravían en los brazos, los contornos cobran relevancia permitiendo que la simetría reclame dignidad y respeto por el individuo. Ingres no busca corregir a la naturaleza porque lo natural no puede incurrir en yerros en la disposición de las cosas. Como lo indica Baudelaire, "[...] no es el Sr. Ingres quien ha buscado la naturaleza, sino la naturaleza quien ha violado al pintor, y esta superior y poderosa dama lo ha domesticado con su ascendiente irresistible". ${ }^{1}$ En Napoleón en su trono imperial se evidencia su respeto hacia lo antiguo, a lo etrusco y su afición por la imagen que logra perpetuarse en el tiempo. Una belleza épica que se expande de manera sobrenatural.

Lo inmaculado de la belleza de Ingres se extravía bajo el horizonte de la pintura moderna. Cézanne reemplazará la luminosidad y gratitud hacia la mujer

${ }^{1}$ Baudelaire (2005), p. 221. 
con sombras y violencia. El orden natural de las cosas se interrumpe con la intervención del ser humano, que contingentemente ocasiona asesinatos y estrangulamientos de mujeres, como ocurre en Mujer estrangulada. La perplejidad de la mirada de Ellen Andrews en El ajenjo de Degas refleja su aislamiento con el mundo. La fineza de los contornos se diluye en el escepticismo y lo perdida de su mirada. Un enfoque desprovisto de la belleza ingresiana, ajeno a la simetría clásica, situando a los personajes solo a una esquina superior del fresco, que se distancia de la necesidad de llamar la atención por mucho tiempo.

Baudelaire advierte con razón que la belleza premoderna proviene de una naturaleza "[...] abstracta e indefinible como la de la única mujer antes del primer pecado". ${ }^{2}$ Sin embargo, los estándares de la belleza se ponen a prueba en la pintura moderna. Ahí los desnudos femeninos constituyen traducciones de la pérdida de la castidad de la mujer, aceptándola ya en el pecado. Olympia y Desayuno sobre la hierba de Manet reflejan esta perspectiva. La belleza sobrenatural de una diosa se sustituye con la imagen de una prostituta parisina y el autor se permite renunciar a alegaciones de corrección normativa, ya que el tema del desnudo de la mujer es únicamente una excusa para pintar. De igual manera, el retrato de una mujer desnuda acompañada de dos hombres que conversan entre sí e ignoran a la mujer con sus miradas, mientras se encuentran sentados a orillas del Sena, es un desnudo que traiciona a la castidad. La mujer mira al espectador interpelándolo, sin buscar trascender virtuosamente más allá de ese particular momento. Los cuadros de Manet marcan la modernidad en la pintura, ya que en ella se pierde el tema que concentra la preocupación premoderna. De acuerdo con Émile Zola, "[1]os pintores, y especialmente Édouard Manet, que es un pintor analítico, no comparten la obsesión de las masas por el tema: para ellos, el tema es sólo un pretexto para pintar, mientras que para las masas sólo existe el tema". ${ }^{3}$

Esta misma inquietud fue develada por Michel Foucault al interpretar a Las Meninas de Diego Velázquez. Según su lectura, existía una invisibilidad sobre lo que hay detrás de dicha pintura, dado que no es evidente qué se quería exactamente representar por su autor con aquella contingente visita de la infanta Margarita de Austria a sus padres en el taller del pintor sevillano. Quizás no se encuentre disponible un esquema teórico para dar cuenta de este cúmulo de rostros, miradas y gestos. De modo tal que puede que "[...] exista en una representación de la representación clásica y la definición del espacio que ella abre". La pintura comienza a pensarse a sí misma, invitando a su espectador a participar de la representación que aquella envuelve. Quien observa a dicha pintura se subsume en una composición de conocimiento, participando de la pintura y diluyendo la doble reflexividad. La supresión de esta dualidad de la

\footnotetext{
${ }^{2}$ BAUdelaire (2005), p. 362.

3 ZOLA (1997), p. 41.

${ }^{4}$ Foucault (1997), p. 25.
} 
representación sostenida por quien observa al cuadro, permite que "[...] la representación puede darse como pura representación". 5

Bajo estas consideraciones, el contraste propuesto por Baudelaire pareciere admitir su pertinencia epistémica en el escenario pictórico. El orden natural no puede neutralizar al despliegue de un pintor transgresor como lo es el moderno. La belleza se disocia de una imagen natural y pura, presentándose abierta a exploraciones de la inquietud moderna. La fugacidad cedió a favor de desprender a lo sensible de lo natural, invitando al pintor a cuestionar tal estado de cosas. Su progresivo cuestionamiento no será abandonado en el desenvolvimiento de esta disciplina, ya que se ajusta con el hombre de mundo. En efecto, la distinción entre comprensiones sobre la pintura produce una ruptura en los cánones estéticos que resulta irreversible en la tradición artística de occidente. En estos términos, el objetivo del presente trabajo es determinar en qué sentido es razonable evaluar este tránsito hacia el ámbito de la reflexión sobre el derecho. Sostendré que el fenómeno jurídico admite ser tematizado a la luz de una comprensión premoderna y otra moderna, visiones que si bien no pueden clausurarse conceptualmente, esgrimen postulados rivales que marcan su diferenciación. No obstante el valor explicativo del contraste, existen problemáticas donde los postulados de la perspectiva premoderna pueden resultar satisfactorios frente a propuestas modernas, del modo en que ocurre con algunas discusiones contemporáneas sobre la identidad del derecho privado.

En las siguientes secciones formularé los postulados de identificación de ambas comprensiones sobre el fenómeno jurídico y, a continuación, evaluaré en qué sentidos el contraste entre ambas concepciones podría presentar dificultades que no estaban presentes bajo la reflexión estética.

\section{Monismo y dualismo jurídico}

Ludwig Wittgenstein estableció que para clarificar a los diversos términos lingüísticos, la actividad filosófica debía renunciar a las definiciones exhaustivas y abocarse a mostrar las prácticas lingüísticas cotidianas en virtud de las cuales se utilizaban dichas nociones. ${ }^{6}$ Tras la complejidad de los juegos de lenguaje que develan formas de vida adscritas a tales proposiciones, existen perspectivas manifestadas en los distintos usos de las palabras. ${ }^{7}$ Las nociones de 'premoderno' y 'moderno' no escapan a tal consideración wittgensteiniana. En lugar de clausurar a ambos términos con definiciones construidas en términos de condiciones necesarias y suficientes de aplicación, podría resultar más provechoso mostrar los postulados de acercamiento a ambas concepciones sobre el ámbito jurídico. El lugar común de estas proposiciones radica en su diseño adversarial. La

${ }^{5}$ Ibid.

${ }^{6}$ WitTGGENSTEIN (2004), §30-31; 43; 60-71.

${ }^{7}$ Ibid, $\$ 23$. 
formulación de un cierto postulado por parte de la concepción premoderna sobre el derecho, encuentra inmediatamente a su rival en el respectivo postulado que defiende la perspectiva moderna sobre el fenómeno jurídico.

Veamos, entonces, cuáles son las proposiciones lingüísticas asociadas a las nociones de premoderno y moderno en la reflexión jurídica. Los postulados que identifican a la comprensión premoderna de lo jurídico corresponden a los siguientes:

1. Déficit de distinciones entre (i) sociedad y naturaleza y (ii) leyes de normativas y leyes de la naturaleza, bajo el contexto de una sociedad cerrada.

2. Déficit de diferenciación entre ámbitos de competencia (i) legislativa y (ii) judicial y, asimismo, concepción de las reglas como resúmenes.

3. Identificación del derecho con la razón. Afirmación de la vigencia de una relación intrínseca entre lo jurídico y la razón.

4. El derecho se entiende como manifestación de la recta razón y de la naturaleza que tiene necesariamente un carácter virtuoso y justo.

De manera que los postulados que compiten por una explicación más acabada sobre el derecho, desde un prisma moderno, serían los siguientes:

1. Diferenciación entre (i) sociedad y naturaleza y (ii) leyes de normativas y leyes de la naturaleza, en el marco de una sociedad abierta.

2. Demarcación entre ámbitos de competencia (i) legislativa y (ii) judicial. De igual modo, se concibe a las reglas como prácticas.

3. Distinción conceptual entre el derecho y la razón. Se sostiene que la relación entre lo jurídico y la razón corresponde a un estatus extrínseco.

4. El derecho es interpretado como manifestación de un acto institucional de voluntad política, por lo cual se concibe como una creación humana contingente y artificial.

Como se podrá apreciar, no se trata de una discusión meramente terminológica, sino que cada comprensión individúa de un modo distinto al derecho como objeto de estudio, desplegando una racionalidad contrapuesta para dar cuenta de aquel. Tampoco los sucesivos enunciados están formulados en torno a una relación de implicancia lógica. Al examinar a una determinada comprensión sobre lo jurídico, no resulta necesario constatar la presencia de la totalidad de los postulados antes indicados. Más bien, la calificación puede operar en uno y algunos postulados, y no así en el o los restantes enunciados de acercamiento. Se trata de mostrar formas distintas de hablar sobre el derecho y no así de definirlas.

Comencemos con el examen de la relación entre los primeros postulados de aproximación. Karl Popper configuró un marco teórico bifronte relativo a estructuras sociales diferenciadas. Existirían dos tipos de sociedades: de un lado, 
una sociedad cerrada y, de otro, una sociedad abierta. ${ }^{8}$ Una estructura social cerrada corresponde a una cultura tribal que sostiene una concepción germinal sobre el fenómeno jurídico, considerando bajo un carácter inevitable a la tradición o a las costumbres, por lo que corresponde entender a las normas jurídicas de la misma forma. Este esquema social asocia a las leyes que rigen en la naturaleza a las leyes que gobiernan en la sociedad. De modo que la norma jurídica adquiere un sentido místico, en la medida en que la sanción establecida frente a la infracción de la regla se estima como inevitable, como si una deidad sobrenatural la decretare. Se confunden los sucesos sociales con la inevitabilidad del mundo natural. Así, todo elemento cultural es naturalizado, en el sentido que es incorporado a la imagen general del mundo natural, y de ahí que el derecho sea también incorporado a la estructura natural que rodea a los individuos. Tal sociedad se caracteriza por sostener un monismo ingenuo en el momento de tematizar al fenómeno jurídico. ${ }^{9}$

El monismo ingenuo importa una agrupación conceptual entre órdenes distintos de cosas. El ámbito social se reduce al natural, unificación que es correlativa a establecer una relación analítica entre las normas que rigen bajo ambos campos. Existen distintos tipos de leyes. Las leyes normativas, es decir, aquellas que son creadas por un grupo dotado de autoridad, buscando influir en el comportamiento de sus destinatarios situados en el mundo social y que carecen de valor veritativo. ${ }^{10} \mathrm{Y}$, a su vez, las leyes de la naturaleza que describen regularidades sobre el curso de acontecimientos naturales, siendo susceptibles de juicios de verdad o falsedad. Pero esta última clase de leyes disuelve la normatividad identificadora de lo jurídico, ya que si la hipótesis se incumple, corresponde modificar a la ley y no así al suceso natural que dicha ley de la naturaleza busca explicar. La divergencia entre ambos tipos de normas es tan evidente que Popper indica que "[...] solo metafóricamente puede denominárseles como leyes". ${ }^{11}$ De modo que la ingenuidad de esta posición monista se refleja en el carácter irreflexivo de la conciliación entre ambas sedes y sus respectivas dimensiones de regulación. ${ }^{12}$

${ }^{8}$ POPPER (2006), p. 72 y ss.

${ }^{9}$ Ibid, p. 74.

${ }^{10}$ Ibid, p. 73.

11 Ibid, p. 77.

${ }^{12}$ De igual modo, la relación entre los principios de causalidad e imputación revisados por Hans Kelsen en sus estudios sobre la ciencia del derecho, revelan la demarcación entre las leyes de la naturaleza y las leyes jurídicas. Mientras las primeras forman parte de los insumos de la ciencia natural, las segundas identifican a la ciencia normativa. Ambos principios protagonizan la descripción de sus respectivos objetos de estudios, pero representan significados radicalmente distintos, ya que el enlace entre los elementos del enunciado jurídico ha sido establecido por un acto de voluntad y, a su vez, la conexión entre causa y efecto enunciada por la ley de naturaleza está al margen de tal intervención. De ahí que el autor vienés advierta con razón que "[e]sta distinción se pierde en el marco de una concepción del mundo religioso-metafísico". KELSEN (1986), p. 91. Para el desarrollo de esta diferenciación, véase Ibíd., pp. 83-122. 
Una sociedad abierta, piensa Popper, sugiere un tránsito cultural evolutivo sobre el conocimiento acerca del derecho, al formular un dualismo crítico, es decir, reconoce la diferenciación conceptual existente entre el ámbito natural y el ámbito social, así como la distinción entre las leyes de la naturaleza y las leyes normativas, que rigen a una y otra esfera de la realidad, en forma respectiva. Su estándar crítico se manifiesta por el hecho que la fractura es realizada por los integrantes de la comunidad de manera consciente, ya que los agentes logran advertir la independencia entre ambos planos, excluyendo la pertinencia de la asimilación monista. Sencillamente, al analizar a las reglas que son establecidas y aplicadas por los sujetos respecto de aquellas para cuya observancia y sanción se prescinde del individuo, concluyen la legitimidad de su escisión. De acuerdo con esta perspectiva de los hechos no es posible extraer normas, porque el "[...] dualismo crítico insiste, de ese modo, en la imposibilidad de reducir las decisiones o normas a hechos". ${ }^{13}$ Desde proposiciones fácticas sobre estados de cosas, no se pueden deducir proposiciones normativas en necesidad. Debido a que lo natural y lo social corresponden a zonas distintas, de un hecho no se puede seguir una decisión o una regla jurídica. La imposibilidad de deducir el deber ser a partir del ser constituye una consecuencia de la apertura crítica de la reflexión de esta tipología de sociedad.

Si bien Popper no representa a alguna de estas posiciones, introduce con éxito la disputa sobre el examen del fenómeno jurídico. De tal modo, una comprensión premoderna sobre el derecho debiere ajustarse a los parámetros de una sociedad cerrada, afirmando una continuidad entre lo social y lo natural y, a su vez, entender al derecho en términos modernos conlleva adecuarse a los estándares de una sociedad abierta, aceptando la fractura existente entre el plano social y natural, junto a las diversas formas de regulación que rigen en cada ámbito.

Un aspecto significativo de esta tensión entre el monismo y el dualismo en los asuntos jurídicos, se manifiesta en el atractivo que contemporáneamente goza el prisma monista, al buscar traducir la complejidad de nuestras prácticas jurídicas de acuerdo con un criterio explicativo. Así ocurre, por ejemplo, en la filosofía analítica del derecho bajo la cual se formulan estrategias contrapuestas para dar cuenta del derecho. En el seno de esta tradición jurídica se identifican modelos monistas como la aproximación lógico-formal desarrollada por Hans Kelsen relativa a identificar la estructura lógica de las normas, así como las diversas vertientes del realismo jurídico, en sus expresiones americanas y escandinavas, y en la actualidad bajo la jurisprudencia naturalizada, que proponen explicar al derecho como un fenómeno natural, es decir, mediante observaciones y predicciones esgrimidas a la luz de una explicación científica estándar. ${ }^{14}$ Pese a la

13 POPPER (2006), p. 78.

${ }^{14}$ Estos esquemas de comprensión monistas en teoría analítica del derecho pueden encontrarse en KELSEN (1986), pp. 9-37, donde se evidencia la influencia de la construcción de sistemas lógicos del Círculo de Viena; respecto del realismo escandinavo en Ross (1970), pp. 23-52; y, finalmente, bajo el proyecto de naturalización de la teoría del derecho en LEITER (2012), pp. 49-97; 99-124. Por supuesto, hablar de monismo bajo tales prismas devela un desplazamiento hacia otro sentido 
indubitada ubicación contemporánea de tales esquemas de comprensión, que fueron germinalmente desarrollados durante el siglo XX, aquellos develan el privilegio epistémico que todavía se reconoce en establecer una uniformidad del derecho, aun cuando aquella empresa sugiera soslayar la demarcación moderna entre lo natural y lo jurídico.

Sigamos revisando los restantes postulados de comprensión sobre ambas concepciones acerca del fenómeno jurídico.

\section{Prácticas, acciones y reglas}

John Rawls contribuyó a refinar nuestra comprensión sobre el fenómeno jurídico, sugiriendo que existían distintos enfoques para examinar la relación entre los ámbitos de competencias legislativa y judicial. De igual modo como sucedía con la tensión anterior entre naturaleza y derecho, los oficios destinados a la creación de reglas y aquel pensado para su aplicación se pueden asimilar o bien tajantemente demarcar. Según sabemos, es fruto del paradigma ilustrado estimar que el juez actúa como la boca del legislador, limitándose este último a aplicar lo que primero dispuso. De ahí que una posición moderna sobre el derecho alegue la ruptura entre ambos oficios, contrariando a la perspectiva unificadora de la premodernidad.

El objetivo del autor de Teoría de la Justicia radica en explicar la relevancia de una distinción lógica entre (i) la justificación de la práctica y (ii) la justificación de la acción que recae dentro de ella. ${ }^{15}$ Dicho contraste se complementa con una distinción correlativa sobre nuestro entendimiento acerca de las reglas, las que se pueden conceptuar en términos de (i) resúmenes y (ii) prácticas. ${ }^{16}$ Desde luego, existe correlatividad entre dichas distinciones conceptuales, pues de la demarcación entre los ámbitos de justificación se predica la adopción de las reglas como prácticas y, en tanto, la asimilación entre la justificación de la práctica y la acción que en aquella cae, conlleva entender a las reglas como meros resúmenes.

La utilidad de la distinción se refleja en disolver la aparente incompatibilidad entre posturas esgrimidas sobre problemas sobre justificación normativa de instituciones jurídicas, como lo son la legitimación del castigo así como la justificación de la obligatoriedad de las promesas. En el marco de la discusión sobre el castigo existen dos visiones, en principio, irreconciliables entre

de la noción, en que monismo no corresponde a colapsar la distinción entre naturaleza y normatividad a favor de la primera. Aquí el empleo del rótulo 'monista' se adscribe a teorías que articulan su comprensión sobre el derecho basándose en un criterio explicativo. No todo monismo quiere decir lo mismo en los asuntos jurídicos y, de ahí, que la tesis de Kelsen no sea monista en el primer sentido del término, pero sí lo es bajo el segundo. Debo esta clarificación al segundo árbitro anónimo de esta publicación.

15 RAWLS (1974), p. 210.

${ }^{16}$ Ibid, pp. 229-243. 
sí. ${ }^{17}$ Mientras el utilitarismo afirma que la práctica del castigo se justifica en la medida que aquella resulte beneficiosa para la sociedad, incrementando el bienestar general, el retribucionismo sostiene que la aplicación de un castigo es razonable porque el agente ha verificado el supuesto de hecho que conlleva la operatividad de la norma sancionatoria, mereciendo la aplicación del castigo. La legitimación del castigo con su utilidad representa un horizonte que tiende hacia objetivos esperados en el futuro, pero la justificación del castigo en torno a su merecimiento, se sostiene en la culpabilidad del infractor de la norma, que en el pasado ha cometido aquella conducta por la cual se le juzga.

Prima facie la relación entre ambos enfoques es de una recíproca incompatibilidad, mas la distinción propuesta por Rawls persigue precisamente develar que dicha conexión no es tal. Si hablamos de la práctica de castigar, nos situamos en el estadio de la formulación de las reglas jurídicas que establecen la operatividad de los castigos. Su dictación se justifica basándose en consideraciones consecuencialistas, debido a que el establecimiento del castigo se justifica para prevenir conductas estimadas como indeseadas, evitando la proliferación de tales comportamientos. Tales preocupaciones corresponden a la competencia legislativa, que establecerá la regla jurídica basándose en el interés de la comunidad. Sin embargo, de acuerdo con Rawls, "[u]na vez que el legislador decide tener leyes y aplicar sanciones por su violación (según sean las cosas, tienen que existir tanto la ley como el castigo) se erige una institución que contiene una concepción retributiva de los casos particulares". ${ }^{18}$

Al ubicar la discusión bajo la justificación de la acción que recae al interior de la práctica de castigar, la sensibilidad retributiva reclama su pertinencia. La acción de aplicar el castigo es de competencia del órgano jurisdiccional y su actividad se legitima a partir del merecimiento del autor de la infracción para soportar la sanción establecida por la norma. El despliegue de la aplicación del castigo se justifica de un modo independiente respecto de la configuración de la práctica bajo la cual aquel se inserta. Los principios que sirvieron de justificación para definir la práctica legislativa, asociados a la utilidad de establecer castigos frente a la comisión de determinadas conductas, no corresponden a los principios retributivos que legitiman la acción judicial. No existe comunicación entre los distintos principios justificativos, pues se trata de oficios diferenciados. ${ }^{19}$ Será

\footnotetext{
${ }_{17}$ Sobre la justificación normativa del castigo, véase PEREIRA (2010), pp. 241-261.

18 RAWLS (1974), p. 215.

19 Es necesario efectuar una prevención. No existe una relación analítica entre las distinciones relativas a las razones que sirven a la regla y aquellas asociadas al acto; entre legislación y jurisdicción; ni, finalmente, entre utilitarismo y retribucionismo. Aquellas confluyen para dar cuenta de una concepción de lo moderno en el derecho, pero una distinción no implica a otra de ellas. La distinción rawlsiana muestra su rendimiento bajo un espectro general de consideraciones, es decir, cuando pensamos en las razones que justifican a la formulación de una regla y aquellas que constituyen sus condiciones de aplicación. De modo que para nuestros propósitos, no es necesario demostrar que según la tesis de Rawls, por ejemplo, del contraste entre legislación y jurisdicción se sigue necesariamente la distinción entre utilitarismo en la dictación de reglas y
} 
irrelevante que un juez pudiere no admitir la utilidad social de la aplicación de un castigo, frente a la verificación de una conducta, cuyo carácter lesivo fue anteriormente establecido por el legislador. Los criterios a partir de los cuales se decidió la dictación de una regla jurídica no requieren adoptarse también al momento de su aplicación. Ambas funciones son tematizadas en términos premodernos renunciando a su distinción, en cambio, la ruptura entre el oficio legislativo y el judicial descansa en la diferenciación entre justificar la práctica y justificar la acción que reside en su interior.

Según lo indiqué, esta demarcación se encuentra vinculada a otra relativa a dos conceptos contrapuestos sobre las reglas; a saber, reglas como prácticas y reglas como resúmenes. Por una parte, concebir a las reglas como resúmenes implica entenderlas como un conjunto de recopilaciones sobre decisiones pasadas, informando sobre el modo en que se han resuelto una serie de casos particulares. ${ }^{20}$ En términos lógicos, los casos anteceden a las reglas que se limitan a constatar la forma de solucionar a aquellos. Debido a que la regla únicamente contiene resoluciones de casos, el juez inmerso en esta concepción podrá evaluar a la regla, determinando si los casos anteriores han sido correctamente resueltos. Si el caso que enfrenta el adjudicador es considerado como una excepción de la regla, entonces, el catastro de soluciones no puede extenderse hacia este nuevo supuesto.

El carácter premoderno de esta forma de entender a las reglas queda de manifiesto en las tempranas observaciones de Hart, quien estableció que dos rasgos distintivos de un mandado están constituidos por su carácter perentorio y el contenido independiente de las razones para la acción. Tales aspectos son significativos respecto de la legislación y los casos de creación de derecho, porque "[...] el mandato puede ser tomado de la manera como el superior se propuso que fuere tomado: el mandato puede ser aceptado como tal razón perentoria que el receptor obedece sin deliberar sobre los méritos que desde su punto de vista posee lo ordenado". ${ }^{21}$ Una regla como resumen supone la situación inversa. Ellas no son jurídicamente obligatorias porque atienden a razones dependientes del contenido, encontrándose en constante deliberación por las personas. Solo una regla como razón perentoria permite introducir la noción de autoridad, del modo en que sucede con las reglas como prácticas.

Por otra parte, las reglas entendidas en términos de prácticas presuponen que las prácticas son definidas por reglas anteriores, y de ahí que toda acción únicamente cobre sentido como tal en la medida en que estuviere situada dentro de la práctica. ${ }^{22}$ La adopción de esta concepción de las reglas interrumpe toda posibilidad de plantear una eventual excepción, pues no tiene sentido cuestionar la

retribucionismo en su aplicación. Se trata de categorías que pueden ser independientes entre sí, pero que convergen en una imagen moderna acerca de lo jurídico.

20 RAWLS (1974), p. 231.

${ }^{21}$ HART (1982), pp. 255-256.

22 RAWLS (1974), p. 237. 
aplicación de la regla como si fuera un caso excepcional. Un caso no puede alegarse como un ejemplo excepcional, porque bajo el contexto de la práctica no resultan pertinentes las consideraciones excepcionales que conlleven la tematización de las reglas, salvo que la práctica acepte excepciones a la regla y sin que por ello permita reducírseles a meros resúmenes. Un supuesto caso cuenta como tal porque se encuentra en el marco de una práctica que, a su vez, es establecida por reglas. La concepción de las reglas como prácticas hace justicia a la normatividad del derecho, porque bajo un contexto institucionalizado se desplazan las consideraciones que pueden estimarse como válidas para justificar la aplicación de una determinada regla. ${ }^{23}$

La modernidad de esta explicación de las reglas en términos de prácticas también puede desarrollarse a la luz de Hart. La dimensión autoritaria de las reglas significa que su enunciado "[...] se acepta como si constituyere una razón para creer lo que dice, con independencia de una valoración de los argumentos en pro y en contra; es decir, sin una deliberación teórica que considere y valore los méritos o las razones de peso para creer lo que dijo". ${ }^{24}$ Forma parte del prisma moderno del derecho reconocer el carácter perentorio de las reglas, sin atender a su contenido, consolidando su imagen como definitiva. No debemos perder de vista la estrecha conexión que existe entre las reglas jurídicas y su carácter autoritativo, ya que bajo una visión moderna en el derecho su normatividad se reconoce al margen de consideraciones evaluativas asociadas al contenido de aquellas razones que proveen las reglas. Desde tal enfoque, podemos interpretar la lectura que formula Joseph Raz sobre las reglas jurídicas, como mecanismos para formalizar concluyentemente conductas y asegurar su coordinación al servicio de la autoridad del derecho. ${ }^{25}$

A partir de estas observaciones, afirmar la ruptura entre la justificación de la práctica y la justificación de la acción que recae en su interior, conlleva asumir una concepción de las reglas como prácticas. Desde la vereda contraria, negar la ruptura entre los ámbitos de justificación sugiere disolver la demarcación entre el oficio legislativo y judicial, adoptando un entendimiento de las reglas como simples resúmenes. Ya lo adelantamos, mientras el rechazo a la demarcación ayuda a transparentar a la comprensión premoderna del fenómeno jurídico, la

\footnotetext{
23 Acerca del sistema jurídico como sistema institucionalizado, cuyas reglas constituyen razones excluyentes para las acciones de los agentes, véase RAZ (1991), pp. 17-54; 162-168.

${ }^{24}$ HART (1982), p. 261.

25 Según Raz, al garantizar que las personas consideren las manifestaciones autoritativas como razones excluyentes, la autoridad puede satisfacer exigencias de coordinación, abandonando precisamente la lectura de las reglas como meros resúmenes. Así, "[1]a autoridad puede asegurar la coordinación solo si los ciudadanos afectados dejan de lado su juicio y no actúan sobre la base del balance de razones, sino sobre la base de las instrucciones de la autoridad. Esto asegura que todos participarán en un plan de acción, que la acción estará coordinada”. RAZ (1991), p. 73. Sin embargo, como se verá en la sexta sección de este trabajo, en el argumento raziano sobre los propósitos de la teoría analítica del derecho contemporáneo se detectan elementos pre-modernos, pretendiendo obtener una explicación adecuada acerca de la naturaleza del derecho.
} 
distinción entre ambas zonas de justificación da cuenta de una aproximación moderna sobre el derecho.

\section{Razones intrínsecas y extrínsecas}

Puede estimarse como indisputado que el derecho se encuentra vinculado de algún modo a parámetros de racionalidad, pero una nota característica de las comprensiones sobre el derecho que hasta aquí hemos revisado, radica en diferenciar el sentido de la relación que reviste el derecho y la razón. M. J. Detmold ha enfatizado el carácter práctico del razonamiento jurídico, esgrimiendo que el proceso de justificación racional de una decisión judicial se encuentra encaminado a la dictación de la sentencia. ${ }^{26} \mathrm{La}$ argumentación articulada por el adjudicador se desarrolla para efectos de obtener una conclusión, que no constituye una conclusión de conocimientos sobre un determinado estado de cosas, sino una acción cristalizada por la actuación judicial. Mientras un razonamiento teórico se despliega para alcanzar una conclusión sobre conocimientos deseados, el razonamiento en el campo jurídico busca legitimar la sentencia del órgano jurisdiccional.

Los cánones de racionalidad no solo son exigibles al momento de la aplicación del derecho, sino también durante la oportunidad de la generación de las reglas jurídicas. Es trivial asegurar que tanto la definición de la práctica legislativa como la acción judicial que cabe en su interior deben satisfacer reclamaciones básicas de racionalidad. Nuestro interés se encuentra en determinar el estatus de la relación que existe genéricamente entre el derecho y la razón. En este sentido, Detmold tematiza el vínculo de acuerdo con dos modalidades; a saber, relación intrínseca y relación extrínseca. ${ }^{27}$ Una relación intrínseca se genera entre dos términos que están conceptualmente conectados. De modo que el derecho en general y, asimismo, la legislación en particular, se disuelven en la razón. La vinculación entre derecho y razón es interna y, de ahí, que sea configurada como necesaria. En cambio, una relación es extrínseca cuando los elementos involucrados están asociados de manera sintética. Derecho y razón no coinciden conceptualmente, sino que su conexión es externa así como meramente contingente. Ambas cuestiones están situadas en esferas diferenciadas.

Las consecuencias que se siguen de ambos tipos de conexión son drásticamente divergentes. Si la relación es intrínseca, entonces, no puede existir discrepancia entre la legislación y la razón. El campo de la razón invade al jurídico, porque no son sino la misma entidad. El derecho puede resultar invalidado frente a la interrupción de su identidad racional. A su vez, si la relación es extrínseca la existencia de lo jurídico no está sujeta a la observancia de exigencias ligadas a la razón. Toda controversia entre derecho y razón devela la independencia existente

${ }^{26}$ DetMold (1989), p. 436.

${ }^{27}$ Ibid, p. 442. 
entre ambos términos, sin comprometer la validez del fenómeno jurídico. Debido a la complejidad de estas relaciones, Detmold propone analizar los distintos procesos de determinación de ley que tienen lugar bajo un sistema jurídico estándar, y así calificar con propiedad, cuándo se verifica una relación intrínseca y cuándo tiene lugar una relación extrínseca entre derecho y razón. ${ }^{28}$ Los procesos de determinación de ley corresponden a los siguientes:

\section{(i) Proceso adjudicativo}

Este proceso corresponde a la aplicación del derecho vigente a la controversia jurídica sobre cuya resolución se ha reclamado la intervención del juez. La función judicial es principalmente concebida para aplicar el derecho preexistente en el conflicto externo de relevancia jurídica. Si esto fuere así, el juez se encuentra vinculado a la legislación vigente $y$, al existir esta, no podría en estricto rigor, crear derecho nuevo. La aplicación del derecho requiere un derecho preexistente en virtud del cual realizar la operación adjudicativa. De ahí que la vinculación entre el estado de cosas anterior es necesaria respecto de este proceso de determinación. Se trata de un proceso sublegislativo conforme al cual nada que no haya existido con anterioridad se genera. La razón que gobierna la actividad del legislador de un modo u otro es adoptada en la razón de la aplicación judicial. De esta manera opera el artículo 170 No. 5 del Código de Procedimiento Civil al establecer que las sentencias que decidan las causas deben contener, entre otros requisitos, "la enunciación de las leyes, y en su defecto de los principios de equidad, con arreglo a los cuales se pronuncia el fallo". El juez se encuentra conectado con el derecho vigente en el ordenamiento jurídico, ya sea expresado en leyes o bien en principios sustantivos de equidad que también pertenecerían a aquel.

\section{(ii) Proceso consultivo}

De acuerdo con este proceso, se desarrolla un esquema de revisión de un órgano respecto de la actuación ejercida por otro órgano. La declaración de derecho efectuada por un órgano es revisada por otro órgano, suponiendo que quien ejerce el control se encuentra situado en un plano de superioridad jerárquica, respecto de quien formula la declaración objeto de evaluación. También corresponde a un proceso sublegislativo bajo el cual no se generan órdenes de cosas independientes al estado anterior. La razón de la primera declaración se comunica a la razón del acto consultivo, admitiendo que la segunda declaración pueda corregir o revocar a la primera. Así, por ejemplo, ocurre con el trámite judicial de la consulta establecido en el artículo 751 del Código de Procedimiento Civil. Ahí se prescribe que toda sentencia definitiva dictada en juicios de hacienda que no haya sido apelada, se elevará en consulta a la Ilustrísima Corte de Apelaciones respectiva, a la que le corresponde revisar la sentencia en cuenta para el solo efecto de ponderar si aquella se encuentra ajustada a derecho. En otro sentido, la propia legislación procesal ha prescrito en el artículo 775 del Código de Procedimiento

${ }^{28}$ Ibid, pp. 438-442. 
Civil, que los tribunales están facultados, una vez que se encuentren "conociendo por vía de apelación, consulta o casación o en alguna incidencia, invalidar de oficio las sentencias cuando los antecedentes del recurso manifiesten que ellas adolecen de vicios que dan lugar a la casación en la forma". La conexión interna se transparenta al momento de enfrentar la discrepancia entre las dos declaraciones. La reacción radica en la posibilidad de invalidar la declaración que defraude el estado de cosas al cual racionalmente se vincula.

\section{Proceso interpretativo}

Este proceso pretende determinar el sentido y alcance de una norma particular, cuya extensión semántica puede resultar problemática. La interpretación implica una actividad de clarificación que puede formularse por el legislador o bien por el juez. Tal esquema se identifica con un proceso sublegislativo, ya que la aclaración del significado de una disposición jurídica requiere necesariamente de una regla a la cual interpretar. Nuevamente, la razón de la regla jurídica que presenta dudas en cuanto a su significado se identifica con la razón de la declaración legislativa o judicial que determina su genuino sentido. Si hablamos de interpretación legislativa, el artículo 9 inciso $2^{\circ}$ del Código Civil dispone que las "leyes que se limiten a declarar el sentido de otras leyes, se entenderán incorporadas en éstas". De modo que una ley interpretativa tiene una relación interna con la ley interpretada y de ahí su incorporación a esta última. De igual forma, bajo el ámbito de la interpretación judicial, el artículo 19 del Código Civil consagra a dos elementos interpretativos: gramatical e histórico. En ambos incisos de dicha regla legal subyace la vinculación entre la norma objeto de interpretación y la decisión interpretativa del órgano jurisdiccional. En tanto no existan dudas sobre el sentido de la ley, no es lícito para el juez desatender el tenor literal de la disposición, argumentando que consulta su espíritu. No obstante, el intérprete puede recurrir a la intención o espíritu de la ley para ejercer su actividad interpretativa sobre una expresión oscura de la legislación en examen. Como se verá, la razón que mueve a la ley interpretada y la declaración interpretativa se encuentra analíticamente enlazada, tratándose solo de un proceso sublegislativo.

\section{(iv) Proceso legislativo}

Finalmente, este último proceso encarna el proceso legislativo propiamente tal. ${ }^{29}$ Bajo esta perspectiva, se produce una genuina generación de derecho. En este lugar, la determinación de derecho se verifica a partir de su independencia con el derecho preexistente. Según lo señala Detmold, el diagnóstico frente a la realidad jurídica anterior a este proceso legislativo decanta en dos posibilidades. Puede no existir o bien, pese a existir, considerarse como irrelevante. ${ }^{30}$ Existe una interrupción entre la racionalidad anterior del derecho y la racionalidad del derecho creado, esgrimiendo un quiebre decisivo al momento de calificar la

${ }^{29}$ Ibid, p. 440.

${ }^{30}$ Ibid, p. 440. 
comprensión sobre el fenómeno jurídico que este proceso de determinación desempeña. El acto de creación de derecho adquiere ribetes revolucionarios así como emancipadores, escindiendo al derecho nuevo de todo atisbo del orden jurídico anterior. $\mathrm{Al}$ respecto, el artículo $6^{\circ}$ del Código Civil establece que "La ley no obliga sino una vez promulgada en conformidad a la Constitución Política del Estado y publicada de acuerdo con los preceptos que siguen". Es decir, la existencia del derecho únicamente depende de la satisfacción de requisitos procedimentales, asociados a la promulgación y publicación de la ley creada. La validez de la legislación se encuentra desvinculada de su correspondencia con la racionalidad que gobierna el estado jurídico anterior, existente al momento de la dictación de la nueva ley.

Ahora bien, ¿qué hay detrás de estos procesos de determinación de ley? Según Detmold, cada proceso manifiesta una identidad diferenciada y, por tanto, consagra una particular relación entre el derecho y la razón. Al agrupar a los distintos procesos, los signados como (i); (ii) y (iii) corresponden a procesos de razón y, en cambio, (iv) constituye efectivamente un proceso de voluntad. ${ }^{31} \mathrm{El}$ sentido de la relación entre lo jurídico y la esfera racional difiere según se trate de un proceso inserto bajo el primer gran cuerpo de procesos, o bien respecto del único esquema propiamente legislativo. $\mathrm{Al}$ desplegarse un determinado proceso de racionalidad se pretende especificar el derecho anterior, conservando la conexión interna que existe entre la justificación racional del derecho antecedente y la actividad que busca aplicarlo, revisarlo para reafirmar su identidad o bien aclarar su genuino sentido. Por su parte, la efectividad de un proceso legislativo de determinación del derecho descansa en la operatividad de la voluntad. El nuevo derecho es fruto de una decisión política de modo que la racionalidad del ordenamiento jurídico anterior resulta externa y ajena a este proceso de creación jurídica. Será suprimida o desplazada por quien decide generar a la legislación.

Las repercusiones extraídas a partir del carácter del vínculo que exista entre la ley y la razón también se traspasan hacia la comprensión de la función judicial. Detmold ha indicado que el quiebre entre los procesos de determinación se relaciona con diversos entendimientos sobre la aceptabilidad del derecho. Desde la perspectiva de alguno de los procesos de razón se observa la tesis según la cual debemos aceptar lo razonable y, en tanto, desde el proceso de voluntad legislativa, se exige aceptar lo que es razonable aceptar. ${ }^{32} \mathrm{La}$ practicidad del razonamiento jurídico permite que medie una intensa comunicación entre la acción del juez y el sentido común de los ciudadanos, admitiendo que los segundos puedan evaluar el juicio autoritativo del primero. Respecto de ambos, aceptar lo razonable implicaría que el derecho únicamente podría contar como tal, en tanto se ajuste a parámetros predefinidos de racionalidad. A su vez, aceptar lo que es razonable aceptar sugiere que la aceptación de lo jurídico no requiere tanto su correspondencia con la razón, como el cumplimiento de requisitos de validez

31 Ibid, p. 441.

32 Ibid, p. 445. 
establecidos por el mismo sistema jurídico, para que el derecho sea razonablemente formulado como tal. Un proceso de razón intrínseca disolverá la existencia del derecho en su contenido, reduciendo la aceptación del derecho en la descripción de un contenido ideal estimado como valioso. Por el contrario, un proceso de razón extrínseca reservará la pertinencia de la aceptación de la legislación hacia su verificación, mediante la satisfacción de criterios formales establecidos para la generación del derecho.

Tales observaciones contribuyen a dotar de un tercer postulado a las comprensiones sobre el fenómeno jurídico. Una comprensión premoderna sobre el derecho se esgrime en términos de alguno de los procesos de razón, afirmando una relación intrínseca entre derecho y racionalidad y, asimismo, exigiendo aceptar lo razonable y solo aquel derecho que sostenga el vínculo analítico con la razón. Una concepción moderna del fenómeno jurídico, por su parte, restringe su interés al proceso de voluntad política, sobre el cual resulta extrínseca la razón del orden jurídico anterior. Del mismo modo, se proclama aceptar aquello que resulta razonable aceptar, una vez verificadas las condiciones de operatividad jurídica también establecidas por distintos actos de voluntad. ${ }^{33}$

Permítaseme ilustrar el contraste entre ambas comprensiones sobre lo jurídico. Al respecto, Detmold trae a colación un pasaje de sir Edward Coke que manifiesta la identidad premoderna del common law. Según Coke:

"El common law controlará los actos del parlamento, y algunas veces juzgará que son completamente nulos, porque cuando un acto del parlamento está en contra de lo que comúnmente es recto y de acuerdo a la razón, o repugnante, o imposible de ser llevado a cabo, el common law lo controlará, y juzgará que dicho acto es nulo". ${ }^{34}$

Bajo estos términos, la tradición jurídica anglosajona constituye una expresión paradigmática de la premodernidad del derecho. De acuerdo con Coke, el common law podrá ejercer un control y revisión respecto del derecho creado por el órgano legislativo, precisamente porque la conexión entre derecho y razón es intrínseca.

33 Cabe enfatizar que el punto central en cuestión radica en enfrentar la apelación premoderna a la razón y la restricción moderna al proceso de voluntad política. Se trata de mecanismos de legitimación de lo jurídico situados en veredas distintas. Estoy consciente que bajo la filosofía política moderna las coordenadas de origen del derecho han sido identificadas gracias a la conciliación entre la razón y la voluntad. Ello queda patente bajo el prisma de Rousseau y más aún en Hobbes, quien estimó que la superación del estadio natural del ser humano ocurría “[...] en parte por sus pasiones, en parte por su razón” HOBBES (1992), p. 104. A partir del origen de lo jurídico se inaugura el estadio civil. La propuesta interpretativa pudiere construirse en atención a la visión que estos autores sostienen sobre el derecho, pues aunque en su generación participen consideraciones relativas a la razón, la validez del derecho no descansa, en estricto rigor, en aquella. El derecho se desenvuelve mediante una articulación funcional que desplaza su eventual correspondencia a exigencias normativas, centrando su justificación en el rol que cumple para alcanzar un deseado estado de cosas.

34 Detmold (1989), pp. 437-438. 
Si el nuevo derecho defrauda a la identidad recta, racional o efectiva del common law que lo precede, deviene en nulo, aun cuando haya sido dictado producto del ejercicio válido de la potestad legislativa. La razón del common law le resulta interna, impidiendo que pudiere interrumpirse tal conexión por medio de decisiones de voluntad.

Veamos ahora una posición moderna sobre la legislación. Nuestro Código Civil en su artículo $1^{\circ}$ define a la ley bajo los siguientes términos: "La ley es una declaración de la voluntad soberana que, manifestada en la forma prescrita por la Constitución, manda, prohíbe o permite". El concepto de la ley plasmado por Andrés Bello refleja la modernidad del derecho. La ley no manda, prohíbe o permite por ratificar un contenido racional predefinido, sino por corresponder a una declaración de la voluntad soberana. La norma jurídica será válida en la medida que la voluntad del pueblo así lo haya decidido. La decisión política cristalizada en una ley que ha sido manifestada en la forma prescrita por la Constitución Política de la República, goza de una validez independiente de su conexión racional con el estado de cosas preexistente. Una ley vale y resulta obligatoria, pudiendo mandar, prohibir y permitir, simplemente porque así ha sido decidido por la voluntad popular, mediante un moderno proceso de creación legislativa. ${ }^{35}$

\section{Derecho, naturaleza y contingencia}

Durante las secciones anteriores hemos reconstruido a ambas comprensiones sobre el derecho a partir de contribuciones efectuadas por autores que no están necesariamente comprometidos con alguna de las concepciones en disputa. La selección de autores es solo funcional para mostrar cómo operan ambas perspectivas en nuestras prácticas jurídicas. Dicha situación no tiene lugar en el caso de Tomás de Aquino. El Aquinate expresa un enfoque sobre el fenómeno jurídico cuyo carácter responde con propiedad a una aproximación premoderna. Su obra destinada a los asuntos jurídicos versa sobre los problemas decisivos para definir al derecho medieval así como a la tradición iusnaturalista en teoría del derecho. ${ }^{36}$ Desde el punto de vista de la reflexión metafísica, el derecho bajo el prisma premoderno responde a una existencia necesaria, ya que asume que lo jurídico no puede sino presentarse, en la medida en que la fuente de la cual proviene también admite tal carácter. El pensamiento judeocristiano se fundamenta en una relación doméstica entre el creador y la criatura racional. ${ }^{37}$ Del modo como un padre se vincula estrechamente con su hijo, se enlaza el derecho que deriva del creador y sus destinatarios, quienes se encuentran racionalmente conectados a la razón suprema. No obstante, el derecho en clave moderna se

\footnotetext{
35 Una revisión historiográfica de las categorías de la modernidad en el derecho, en atención a la estatalidad del derecho y la transfiguración de la ley, puede consultarse en GROSSI (2003), pp. 21-38. 36 Acerca de la identidad del ordenamiento jurídico medieval, véase Grossi (1996); en especial pp. 59-100; 137-202.

${ }^{37}$ MACINTYRE (2006), pp. 124-126.
} 
ajusta a un conjunto de instituciones y prácticas de carácter contingentes. ${ }^{38} \mathrm{La}$ existencia de lo jurídico puede o no verificarse, debido a que la negación del derecho no implica una contradicción en sus términos. Si el derecho es racionalmente derivado de una fuente inmutable, se sigue la necesidad premoderna del fenómeno jurídico. De lo contrario, en tanto el derecho surja a partir de un acto deliberado de creación humana, su existencia así como su composición se enmarcan bajo la contingencia moderna. Sin embargo, cabe hacer la salvedad que, según lo veremos, Tomás deja espacios para la creación humana legislativa en zonas de determinación de la ley.

Desde luego, para Tomás el derecho tiene una imagen necesaria como virtuosa. La necesidad y bondad suprema del creador garantiza la pertinencia del derecho tanto de su existencia como en su corrección normativa. Para Tomás, el derecho es el objeto de la justicia, admitiendo que la criatura racional debe actuar virtuosamente $y$, en especial, ejerciendo la principal virtud, es decir, la justicia. ${ }^{39} \mathrm{El}$ derecho se encuentra asociado con la igualdad, de manera que tanto el derecho en particular como la justicia en general apelan hacia el equilibrio entre los distintos términos. Derecho o lo justo significa "[...] una acción adecuada a otra acción según cierto modo de igualdad". ${ }^{40}$ De modo que lo jurídico se enmarca en el tipo de relaciones racionales que gobiernan necesariamente a la realidad. El derecho viene dado, al igual que otros elementos de nuestra estructura natural heredada. Tal vínculo se transparenta al detenerse en la tipología de las leyes que formula Tomás en su clásica teoría de las leyes. Como sabemos, las leyes rigen las acciones de las criaturas, porque promueven su bienaventuranza. Es decir, cumplen su función en términos de constituir un estándar de corrección moral para sus destinatarios, pues el creador gobierna a sus criaturas mediante leyes, siendo estos preceptos racionales. En efecto, toda ley para tener fuerza de ley debe corresponder, entre otros criterios, a un dictamen de la razón práctica. ${ }^{41}$

Un aspecto de significativo interés en la teoría de las leyes del Aquinate es la conexión conceptual que existe entre la ley eterna y la ley natural. Mientras la primera devela el esquema de organización bajo el cual el creador pensó al mundo, y cuyo conocimiento se encuentra al margen de las posibilidades de la criatura finita, la segunda corresponde a la "[...] participación de la ley eterna en la criatura racional [...]". ${ }^{42}$ De manera tal que la ley que goza de plena normatividad en el modelo de Tomás, esto es, la ley natural, transparenta que en ella subyacen los criterios y estándares de la legislación eterna. Esta estrecha relación entre el pensamiento del creador y la ley que encamina a los individuos a hacer el bien y evitar el mal, también se traspasa hacia la legislación de mayor influencia en nuestros asuntos morales y jurídicos; a saber, la ley humana. Tomás no fue

38 Tal es, por ejemplo, la aproximación de Hart sobre el fenómeno jurídico. Al respecto, véase, en especial, HART (1963), pp. 1-21; 99-123.

39 TOMÁs III, II-II (a) (2001), p. 470.

40 Ibid, p. 471.

41 TOMÁs II, I-II (2001), p. 712.

42 Ibid, p. 710. 
ingenuo para negar que los seres humanos formularen a sus leyes positivas, de hecho, es tarea del gobernante quien tiene a su cuidado el devenir de la comunidad, promulgar dicha normativa. ${ }^{43}$ La premodernidad del argumento tomista, junto al indicar el carácter necesario, inmutable y virtuoso del fenómeno jurídico, queda de manifiesto en las relaciones entre ley natural y ley humana. ${ }^{44} \mathrm{De}$ un lado, existe una relación de derivación, según la cual toda ley humana es derivada desde la legislación natural. Tal deducción podrá operar según el mecanismo de conclusión, garantizando la consistencia silogística entre los principios naturales y la conclusión extraída a partir de las premisas. De igual forma, podrá derivarse la ley humana por determinación, regulando a zonas de arbitrariedad para el gobernante, cuya esfera de competencia resulta irrelevante para la ley natural.

De otro, una relación de concordancia de acuerdo con la cual una ley que no sea justa, no puede tener fuerza de ley. Tal norma corresponde a una corrupción de ley y no propiamente a una ley. Dicha conclusión es obtenida a partir del axioma agustiniano según el cual "[... la ley que no es justa no parece que sea ley". "La justicia se sigue de su equivalencia con la rectitud normativa, de manera de reducir el problema de la existencia de la regla en su contenido. Una norma humana válidamente promulgada carece de fuerza de ley si su contenido no se ajusta a los principios de la ley natural. Si la legislación humana debe ser derivada desde el derecho natural, este último existe con independencia de los agentes y sobre el cual sus posibilidades de intervención se encuentran drásticamente restringidas. Ahora bien, al atender a la relación de concordancia, se devela que la validez de una regla jurídica se disuelve en su contenido, entendiendo que una ley humana tiene fuerza de ley porque satisfizo las exigencias de la ley natural de la cual inequívocamente aquella deriva.

Estos presupuestos asociados a concebir al derecho como una expresión de la invariable recta razón, cuya vigencia depende de su corrección normativa y concordancia a la ley natural que nos antecede, fueron controvertidos prontamente bajo la filosofía de la moral moderna. El contractualismo apeló a una situación contrafactual para clarificar la relevancia del fenómeno jurídico. Si hipotéticamente nos situáramos bajo un estado de cosas en que no existe lo que de hecho existe entre nosotros, es decir, derecho, podríamos transparentar la relevancia del fenómeno jurídico, como un mecanismo de cooperación y seguridad entre los individuos. Una aproximación estándar en tal sentido descansa en el pensamiento de Thomas Hobbes. El autor de Leviatán efectuó una fisura entre dos estadios. La condición natural del ser humano y el estado civil. Si bien no existe una definición clausurada del estado de naturaleza, Hobbes lo entiende en oposición al estado civil. Donde no existe soberano, cabría sostener

${ }^{43}$ Ibid, p. 708

44 Un acabado examen sobre la relación entre derecho natural y derecho positivo en la teoría del derecho del Aquinate, en BASCUÑ́n (1996), pp. 301-322.

45 TOMÁs II, I-II (2001), p. 742. Cursivas del original. 
teóricamente la presencia de la condición natural del hombre. ${ }^{46}$ Esto explica por qué mientras el estado de naturaleza se caracteriza por la ausencia de justicia, propiedad y derecho, el segundo los contiene, en la medida en que existe un adjudicador que puede determinar qué es lo correcto e incorrecto, así como lo tuyo y lo mío. ${ }^{47}$ El déficit de derecho identifica al estado de naturaleza, porque el derecho es creado y únicamente pertinente en el marco de las instituciones sociales, como ocurre con el Estado. Lo jurídico solo cobra sentido una vez que estamos situados bajo el estado civil, que, a su vez, se encuentra caracterizado por la presencia del soberano. Como se puede observar, el problema radica en determinar bajo qué términos se justifica la existencia del fenómeno jurídico si este puede contingentemente no existir. Y, de hecho, naturalmente no existe.

La descripción de Hobbes sobre la vida en el estado de naturaleza es sugerente. Aquella corresponde a una potencial guerra de todos contra todos. ${ }^{48}$ Es decir, este supuesto no requiere que efectivamente exista conflicto entre los agentes, sino que basta con una disposición manifiesta a la lucha mientras no exista un poder común. Existe una constante guerra bajo la cual el ser humano podría resultar destruido por los demás. Esta contraposición entre el estado de naturaleza y el estado civil se evidencia, en los términos de Hobbes, porque el primer orden de cosas se extenderá "[...] durante el tiempo en que los hombres viven sin un poder común que los atemorice a todos [...]". ${ }^{49}$ Como sabemos, la vida del ser humano fue categóricamente descrita por el autor como "[...] solitaria, pobre, tosca, embrutecida y breve". ${ }^{50}$ De acuerdo con lo anterior, el problema genérico de la condición humana natural radica en su inseguridad. Las pasiones de los hombres pueden conducirlos a su mutua aniquilación y Hobbes identifica al derecho como un mecanismo para abandonar ese supuesto estado. En otros términos, la inseguridad de la potencial guerra se puede resolver mediante un contrato de índole social, adoptando la explicación paradigmáticamente moderna sobre la génesis de la sociedad humana. La mera reunión de individuos deviene en una sociedad propiamente política y el derecho se alza como un instrumento válido para interrumpir al mundo natural, interponiéndolo ahí donde no existe.

Hobbes explica la artificialidad del fenómeno jurídico porque este ya no es derivado, sino puesto por los agentes. ${ }^{51}$ Las categorías de natural y artificial se oponen filosóficamente para determinar situaciones dicotómicas. El derecho es artificial, porque no es natural, es decir, no es parte de la composición natural del mundo. Si atendemos con detención al postulado contractualista hobbesiano, la creación del derecho puede estimarse prudencial, ya que tenemos presente a una

46 HobBes (1992), pp. 102-104.

${ }^{47}$ HobBes (1992), p. 104.

${ }^{48}$ Ibid, p. 102.

49 Ibid, p. 102.

${ }^{50}$ Ibid, p. 103.

51 Esta consideración sobre el derecho moderno o legislado, según la cual aquel es válido porque ha sido puesto, es resaltado en ATRIA (2004), p. 117. 
situación que carece de aquel. Es indudablemente moderno pensar al derecho como aquella clase de cosas que pudiere no existir, pero aún más propio de una sensibilidad moderna, esgrimir que su justificación debe encontrarse en su funcionalidad y no así en el valor de su contenido. El derecho como todo constructo moderno se justifica basándose en la función que aquel cumple. Como lo sugiere Niel MacCormick, "[...] los artefactos e inventos humanos, incluyendo las reglas bajo las que las personas tratan de vivir, o conseguir que otras vivan, tienen que ser entendidas funcionalmente". ${ }^{52}$ La intuición hobbesiana sobre el derecho es que este resuelve un problema de cooperación, relativo al aseguramiento de nuestra conservación, a partir de la celebración de una figura también paradigmáticamente moderna, como lo es un contrato. La fractura entre lo natural y lo artificial es evidente. La igualdad natural que aproximadamente existe entre los individuos es reemplazada por la desigualdad entre quien dicta leyes y quienes las obedecen. El derecho es concebido como un instrumento para salir de esta inseguridad generalizada entre los distintos seres humanos. De ahí que la función del contrato es permitir a los agentes abandonar su estado natural, mediante la "[...] mutua transferencia de derechos [...]". ${ }^{53}$ A ello los hombres llaman contrato. Se trata de un fenómeno cuyo estatus es asignado externamente por los agentes que lo suscriben, así el derecho en Hobbes adquiere su dimensión de hecho institucional. ${ }^{54}$ Su concepción es instrumental, porque el derecho sirve a los hombres "[...] de instrumento para proteger su vida contra sus enemigos". ${ }^{55}$

Las variantes del pensamiento contractualista han contribuido para explorar otras dimensiones de este artificio denominado derecho. Si bien en Hobbes la existencia de lo jurídico es meramente contingente, y supone un acto de creación colectiva humana que afecta su natural ausencia entre los individuos, el argumento se tiñe de márgenes de heteronomía bajo el estado civil. Una vez instituido el soberano, el derecho corresponde a su voluntad, remarcando el carácter de decisión política y existencia no necesaria a los cuales responde. Pero podría resultar cuestionable que los súbditos deban obedecer incondicionadamente al soberano por meras razones estratégicas, o bien porque estiman más prudente obedecer que desobedecer, si su seguridad se encuentra en juego en el cumplimiento del contrato social. Después de todo, con la celebración del contrato han renunciado a sus libertades mas no a sus vidas. En Hobbes aún se conserva el prisma premoderno bajo el cual lo jurídico se encuentra en tensión con la libertad y autonomía de los agentes. Aquello fue en parte corregido con los planteamientos de Jean-Jacques Rousseau.

Rousseau replica el diagnóstico hobbesiano sobre un estado de naturaleza en que la preservación de la especie humana está en riesgo. La posibilidad de enfrentar tal peligro nuevamente se basa en la solución moderna del contrato social. De acuerdo con Rousseau, "[e]sta suma de fuerzas sólo

\footnotetext{
52 MACCORMICK (2011), p. 376.

${ }^{53}$ HobBes (1992), p. 109.

54 Respecto de la distinción entre hechos brutos y hechos institucionales, véase SEARLE (1997), pp. 49-74.

${ }^{55}$ HOBBES (1992), p. 106.
} 
puede surgir de la cooperación de muchos [...]". ${ }^{56}$ Así, el derecho es situado de manera artificial a partir de un cúmulo de voluntades particulares que se unen en un todo indivisible que da cuenta de la voluntad general. La voluntad general opera como estándar normativo de autonomía, ya que los individuos renuncian a la libertad natural que poseen, para ganar su libertad moral, es decir, "[...] la única que convierte al hombre verdaderamente en amo de sí mismo, porque el impulso exclusivo del apetito es esclavitud y la obediencia a la ley que uno se ha prescrito es libertad". ${ }^{77}$ El ideal regulativo del autogobierno según el cual los agentes únicamente se gobiernan de acuerdo con sus propios dictámenes, es consistente con la artificialidad del fenómeno jurídico. Bajo un prisma moderno, el derecho no tiene por qué contraponerse a la libertad de los agentes ni tampoco renunciar a toda posible dimensión de autonomía de sus destinatarios. Gracias al derecho es posible obligarse y el mérito de tales obligaciones es que fueron autónomamente formuladas. ${ }^{58}$

El panorama contrapuesto hasta aquí presentado pudiere estimarse como satisfactorio al admitírsele como una estrategia teórico-metodológica para develar dos formas de entender a lo jurídico. Su rendimiento explicativo es indudable. No obstante, la operatividad de la distinción entre una concepción premoderna y otra moderna presenta ciertas dificultades. Permítaseme ejemplificar lo anterior con la obra de Ronald Dworkin. Sus planteamientos pueden considerarse, junto a John Finnis, como las expresiones de mayor repercusión en las comprensiones premodernas sobre el derecho en la teoría jurídica analítica contemporánea. Anteriormente se indicó que no existe una relación de implicación lógica entre los distintos postulados de identificación, así como tampoco un compromiso cronológico entre una posición acerca del derecho y el contexto histórico bajo el cual aquella se articula. El enfoque que sostuvo Dworkin en sus investigaciones sobre filosofía del derecho admite calificársele como premoderno, pero de aquello no se sigue que suscriba a cada uno de los diferentes postulados que hemos revisado como parte de tal comprensión.

La tesis dworkiniana llama nuestra atención en la adjudicación. Invita a disolver a la teoría del derecho en una teoría de la adjudicación. Según Dworkin, la versión del naturalismo que él defendió se trataba de una teoría sobre cómo deberían formularse las decisiones judiciales. De modo que el ser del derecho depende de lo que este debiere ser. ${ }^{59}$ Gracias a su identidad interpretativa, lo jurídico se encuentra conectado con la mejor justificación posible de las prácticas jurídicas. ¿Cómo podría operar la implementación del esquema sobre sus distintos órdenes de consideraciones? Respecto del primer postulado de una perspectiva

56 ROUSSEAU (2007), p. 16.

${ }^{57}$ Ibid, p. 22.

58 Con todo, la versión más acabada de conciliación entre derecho y libertad se sitúa en las consideraciones kantianas. De ahí que su principio universal de derecho procure la coexistencia de las libertades recíprocas de los distintos arbitrios, bajo una ley universal de la libertad. Al respecto, véase KANT (2005), pp. 37-43.

${ }^{59}$ DwOrkin (1990), p. 23. 
premoderna sobre el derecho, Dworkin no incurrió en la confusión conceptual entre la esfera natural y la cultural de la realidad. Pese a la denominación de naturalismo a su posición sobre los fallos, el autor efectuó una demarcación entre las proposiciones descriptivas que rigen a los fenómenos naturales y las prescripciones que gobiernan a la sociedad. Su aproximación es más propia de un dualismo que de un monismo jurídico. De modo que ya tendríamos un postulado de identificación no atribuible a la postura de Dworkin, pese a nuestra preliminar calificación de premoderna. Veamos, a continuación, en qué sentidos correspondería denominársele en tales términos.

El desarrollo de la teoría sobre la adjudicación dworkiniana apostó por consideraciones asociadas a la negación de la ruptura entre el ámbito de justificación de la práctica y la justificación asociada a la acción que bajo aquella reside. Debido a que el derecho es uno de los tantos conceptos interpretativos disponibles, todo intento de formular juicios descriptivos acerca del derecho, importa ineludiblemente esgrimir juicios evaluativos o de índole interpretativa. ${ }^{60} \mathrm{~A}$ diferencia de la teoría del derecho defendida por Hart que era de carácter general y descriptiva, Dworkin sugirió la pertinencia de esgrimir una teoría del derecho particular y evaluativa. ${ }^{61}$ Una correcta explicación sobre el fenómeno jurídico debía hacerse cargo de la posibilidad de modificar a dicho objeto de estudio. De manera que cuando los jueces deciden los conflictos jurídicos sometidos a su conocimiento, responden a exigencias normativas sobre a cuál estado de cosas dentro del marco jurídico debiéremos aspirar. La comunidad de jueces compromete sus convicciones morales y políticas en sus decisiones, debiendo otorgar el mejor sentido posible al fenómeno jurídico. Así, los principios que justificaron la definición de la práctica legislativa deben ser también equivalentes a aquellos que legitiman a la actividad judicial. Es un deber judicial cumplir con el estándar normativo de corregir a la práctica jurídica, entendiendo que en su función judicial puede dotarla de consideraciones para hacer de ella la mejor versión que se encuentre disponible entre las diversas prácticas interpretativas.

A su vez, las reglas jurídicas son interpretadas en términos de resúmenes y no de prácticas definitorias. Un carácter decisivo de una práctica es que esta no se encuentra expuesta a ser evaluada en torno a su mérito, actuando formalmente sobre los agentes mediante un razonamiento exclusionario. Es decir, existe un desplazamiento de consideraciones válidas para ponderar la legitimidad de la práctica general, porque esta ha sido concluyentemente definida por reglas, entendidas como prácticas. Una regla como resumen sí admite tales observaciones, ya que es pertinente deliberar respecto de su corrección. Si el intérprete se encuentra en la necesidad de otorgar el mejor sentido posible al fenómeno jurídico, contribuyendo a su construcción, las reglas no actúan sobre jueces ni juristas como prácticas. Aquello puede ser transparentado mediante la analogía que Dworkin señaló existir entre la confección de una novela en cadena

${ }^{60}$ DWORKIN (1988), pp. 44-71.

${ }^{61}$ HART (1997), pp. 227-229. 
y la cadena del derecho. ${ }^{62}$ Si un grupo de novelistas se dividen la articulación de una novela, cada uno va a trabajar mediante el material previamente proporcionado por su compañero, quien trabajó sobre la parte anterior. $\mathrm{Al}$ pensar en una novela con una introducción, tres capítulos y una conclusión, obtenemos una empresa colectiva entre los novelistas. Pero la ejecución progresiva de tal empresa conlleva ajustarse a la pretensión de corregir el material literario suministrado por el respectivo compañero. Mientras al autor del primer capítulo no le corresponde solo desarrollar el capítulo inicial de una forma satisfactoria, sino que además le compete hacerlo en atención a la introducción ya escrita. Su tarea es de refinar lo que antes se ha hecho. El autor de la conclusión, en tanto, tendrá que robustecer todo el material que le antecede, realizando una clausura de la obra adecuada para completar el proceso literario y, asimismo, otorgando el significado más excelso posible tanto a la introducción como a los capítulos sobre los cuales centró sus esfuerzos.

Por supuesto, Dworkin no considera que su teoría del derecho sea una posición acerca de la interpretación de novelas. No obstante lo cual, la analogía es reveladora para conocer sus propósitos teóricos. Según el autor, "[...] el naturalismo supone que la adjudicación en el common law es una empresa en cadena que comparte muchas de las características de la historia que hemos inventado". ${ }^{63}$ Los jueces adoptan decisiones creativas conservando lo anterior, formándose una opinión sobre el proceso colectivo y, fundamentalmente, mejorando tanto los insumos proporcionados por los intérpretes previos, como la obra en su conjunto. Tal tarea interpretativa no es tanto estética como política, pues vincula a la moral política de los jueces partícipes del proceso. De modo tal que, al depender las decisiones judiciales de las concepciones políticas de los jueces, estos pueden llegar a diferentes interpretaciones de las decisiones pasadas, porque pueden diferir tanto de cual cuenta como mejor adecuación de la regla a los hechos, como por la legitimidad sustantiva de la misma regla. Las reglas y las decisiones jurídicas participan de dicha evaluación posterior, desarrollando así una empresa heurística. Los ideales sustantivos de la moral política de la comunidad de jueces devela la pertinencia que existan controversias interpretativas. Después de todo, el desacuerdo entre sus integrantes es más bien teórico que empírico, ya que aun cuando pudiera sostenerse que aquellos discuten sobre las distintas declaraciones de ley, lo hacen sobre cuál es la mejor interpretación posible de tal declaración. ${ }^{64}$

El tercer postulado de una comprensión premoderna es cubierto en el planteamiento de Dworkin. El derecho supone una empresa conectada racionalmente a un estado anterior de cosas. Ya indicamos que Coke situaba como un expresivo ejemplo de una postura premoderna sobre el derecho a la formulación del common law. Más atrás hemos señalado que el naturalismo de

${ }^{62}$ DwORKIN (1990), pp. 25-27.

${ }^{63} \mathrm{Ibid}$, p. 26.

${ }^{64}$ Sobre el contraste entre desacuerdos empíricos y teóricos en el derecho, véase DwORKIN (1988), pp. 15-43. 
Dworkin es una teoría sobre la adjudicación vigente precisamente en dicha tradición jurídica. Esta cuestión se encuentra en consonancia con los procesos de determinación de derecho que Detmold identificó como manifestaciones de los procesos de razón, en contraste con el proceso de voluntad moderna. Las nociones de adjudicación, consulta e interpretación se sitúan como términos que presuponen un estado anterior, sobre el cual las decisiones judiciales, declaraciones consultivas y propuestas interpretativas, están racionalmente vinculadas. La conexión entre derecho y razón en Dworkin es necesariamente intrínseca y ello explica por qué el juez se encuentra conectado con las formulaciones que le anteceden, pero siempre tiene el deber de velar por la corrección interpretativa de su decisión y del sistema jurídico en su conjunto. Se disuelve la validez de lo jurídico en la racionalidad de su contenido. Si hay correspondencia entre ambas esferas, el juez aplicará a la regla jurídica, pero si no existiere, la labor judicial apelará a corregirla, formulando una declaración que restaure la conexión racional fundante. La razón que gobierna al derecho debiere ser también la razón de su aplicación e interpretación.

Finalmente, en el último postulado también aparecen otros problemas de su aplicación. Las exigencias imperativas de interpretación sobre el fenómeno jurídico responden evidentemente a consideraciones normativas. Si el juez compromete en sus fallos a sus convicciones morales y políticas, su tarea interpretativa sobre el derecho se encuentra encaminada a hacer de lo jurídico un esquema más correcto y justo. Dworkin no solo promueve un regreso a una versión del derecho natural, desarrollada bajo la reconstrucción de su naturalismo, sino que también comparte con Tomás la expectativa de justicia bajo la cual el derecho cobra su existencia y genuino sentido. Esto se clarifica al atender a la dimensión evaluativa de lo que cuenta como mejor interpretación. La calificación de una propuesta interpretativa como 'mejor' se sigue de su concordancia con exigencias de justicia correctiva. El fenómeno jurídico está vinculado con ideales de justicia que comparte la comunidad de jueces. De ahí que la "[...] mejor interpretación de las decisiones judiciales pasadas es la interpretación que las muestra con la mayor lucidez, no estética sino política, acercándolas lo más posible a los ideales correctos de un sistema legal justo". ${ }^{65}$ Ambos, Tomás de Aquino y Ronald Dworkin, asumen que es posible influir en la determinación de lo que cabe considerar como derecho. La justicia constituye un criterio sustantivo para clasificar a lo jurídico de aquello que no corresponde denominarse como tal.

Sin embargo, la adhesión de Dworkin a criterios conceptuales de lo premoderno en el derecho no es completa bajo este ulterior postulado. Si bien conecta el sentido interpretativo del derecho al cumplimiento de interpretaciones que conviertan al derecho en prácticas más justas, no por ello entiende que el derecho es un producto de la recta razón de un creador. La conexión necesaria entre derecho y justicia no se fundamenta en una relación de derivación existente entre el creador y su criatura racional. Ello se manifiesta con claridad en el hecho

${ }^{65}$ DwORKIN (1990), p. 26. Cursivas mías. 
de que Dworkin no suscribió una imagen metafísicamente necesaria e inmutable del derecho, permitiendo la introducción de valoraciones normativas de los participantes en los momentos de estudio y adjudicación. De igual manera, los caracteres de contingencia y artificialidad no son negados en los planteamientos de Dworkin. La conexión del derecho a ciertos dictámenes de justicia y su ubicación bajo las prácticas judiciales del common law, no resultan categóricas para desvincular a su teoría del derecho de la tesis según la cual el fenómeno jurídico ha sido creado y situado artificialmente por los agentes. Como se podrá apreciar, la vinculación de Dworkin a una posición premoderna sobre el derecho puede ser sostenida, pero tomando las precauciones que tal esquema metodológico no logra advertir las distintas dimensiones de su pensamiento. La calificación de su aproximación acerca del derecho como premoderna, contribuye a interpretar las diversas modalidades bajo las cuales formuló a su comprensión sobre los asuntos jurídicos, en términos premodernos. En lugar de agotar a su teoría sobre el derecho, este esquema de análisis nos ayuda satisfactoriamente a develar cuál es el sentido de dicha comprensión.

\section{Escisión en teoría del derecho y teoría del derecho privado}

Durante el transcurso de las secciones anteriores, hemos desarrollado los distintos postulados de identificación de una comprensión premoderna y otra moderna de lo jurídico. Asimismo, se han establecido ciertas dificultades que enfrenta la operatividad de tal distinción, tomando como ejemplo de estas tensiones la obra de Ronald Dworkin. Su óptica acerca del derecho admite entenderse como premoderna, no obstante ubicarse bajo la reflexión jurídica contemporánea y no adscribir a la totalidad de postulados que están en disputa bajo este marco dual de análisis. En esta sección final se discutirá sobre la razonabilidad de la distinción. Desde un plano descriptivo acerca de la diferenciación de los postulados y funcionamiento de su aplicación, corresponde transitar hacia consideraciones de segundo orden. Tales observaciones dicen relación con evaluar en qué sentido conviene adoptar una comprensión sobre el derecho en desmedro de su perspectiva rival. Un diagnóstico preliminar sobre este desafío debiere argumentar en torno a la aceptación de un prisma moderno sobre el derecho, como una explicación más satisfactoria del fenómeno jurídico que la entregada por una concepción premoderna. Cabe preguntarse si es necesariamente de tal modo.

La reflexión sobre la belleza se condujo de un modo distinto a cómo han devenido las investigaciones acerca del derecho. Baudelaire promovió una escisión entre el arte premoderno y moderno, esgrimiendo un giro radical respecto del concepto de belleza al cual suscribían los distintos autores bajo su bifronte taxonomía. Cuando la estética inició el proceso de autocomprensión que actualmente la caracteriza, brindó buenas razones para adjudicar la disputa a favor de lo bello, como es modernamente entendido. La expectativa de una belleza natural, inmutable y virtuosa resultó en demasía desplazada por cánones transgresores relativos a la irrupción de la falta de posicionamiento de los 
individuos en el mundo moderno. Entender a la belleza bajo los términos de contingencia, desconcierto y pecado permitió a la disciplina sensible refinar nuestra comprensión sobre sí mismos, de cómo somos y cómo actuamos. De manera tal que la adjudicación en la teoría del arte cedió a favor de las consideraciones modernas sobre la belleza. Tal estado de cosas se estimó como irreversible, porque las razones para entender a lo bello bajo los criterios modernos se mostraron de un modo satisfactorio y más pertinentes a la sensibilidad de la estética moderna. En lo que sigue, se evaluará en qué sentidos la ruptura estética presenta una solución de continuidad con la fractura propuesta entre las dos versiones sobre el fenómeno jurídico.

La irreversibilidad en el tránsito de los prismas bajo los cuales se entienden a las investigaciones estéticas, no puede comunicarse sin dificultades hacia las comprensiones sobre el derecho. Si bien la distinción entre lo premoderno y moderno del derecho es teóricamente valiosa, no necesariamente conviene adoptar una posición moderna sobre lo jurídico, para comprender de manera adecuada al derecho. Según se mostrará más adelante, mientras en teoría jurídica analítica algunas aproximaciones premodernas sobre el derecho comprenden erróneamente a la individuación de lo jurídico, no resulta descartable que bajo la filosofía del derecho privado contemporáneo existan buenas razones para apostar por un modelo premoderno frente a las observaciones esgrimidas por posturas modernas sobre la estructura y propósitos del sistema jurídico privado. Revisemos este escenario de consideraciones contrapuestas.

Bajo la tradición analítica de la filosofía del derecho se han desarrollado una serie de momentos de autocomprensión. ${ }^{66}$ Por tales momentos entiendo un proceso en que mediante consideraciones de segundo orden, la teoría jurídica analítica ha comenzado a pensarse a sí misma, formulando un ejercicio de autorreflexión. Sus esfuerzos han sido focalizados en determinar el objeto de estudio de la teoría del derecho, los propósitos que cabría esperar de dicho quehacer, así como la metodología idónea para alcanzarlos. Un primer momento de autocomprensión puede situarse con la publicación del Post Scriptum a la segunda edición de El Concepto de Derecho en 1994. Como se sabe, ahí Hart se defendió de parte de las críticas formuladas por Dworkin desde 1977, abriendo el debate mediante una sección titulada como "Naturaleza de la Teoría Jurídica". Según los planteamientos plasmados en este póstumo texto, una explicación del desacuerdo entre Hart y Dworkin es el tipo de teoría del derecho que Hart defendió en la publicación original de su obra en 1961 y que Dworkin rechazó en Los Derechos en Serio. Mientras la teoría del derecho de Hart revestía los caracteres de general y descriptiva, la reflexión jurídica dworkiniana era localista y evaluativa. $^{67}$ Tales consideraciones develan que se trataba de un proceso de autorreflexión en que la tematización opera respecto de las posiciones jurídicas ya

${ }^{66} \mathrm{El}$ ejercicio de reconstrucción de la tradición analítica de la filosofía del derecho, en términos de sus tensiones y momentos de autocomprensión, se encuentra en PEREIRA (2014), pp. 283-322.

${ }^{67}$ HART (1997), pp. 227-232. 
expresadas por ambos autores, situando a la propia teoría del derecho como objeto de su reflexión.

Un segundo momento de autocomprensión bajo la jurisprudencia analítica contemporánea puede ubicarse en el trabajo intelectual que Joseph Raz generó entre los años 1996 y 1998, y cuya sistematización operó en "Can there be a theory of law?”, originalmente editado en el año 2004. En dicho lugar, Raz sugirió que la teoría analítica del derecho debía abandonar al análisis conceptual para calificar a su despliegue teórico como exitoso. Esta metodología fue tributaria de las investigaciones de Hart desde mediados del siglo XX, entendiendo que la teoría del derecho se preocupaba de proporcionar una explicación robusta acerca del significado del término 'derecho'. Bajo tal perspectiva, la reflexión jurídica debiere responder a la pregunta "¿qué es 'derecho'?", en circunstancias que las pretensiones de la teoría del derecho, como toda empresa genuinamente teórica, debieren encaminarse a esgrimir una explicación universal y necesaria sobre el fenómeno jurídico. El enfoque raziano pretende reubicar las preocupaciones de la filosofía analítica en la respuesta de otra pregunta de mayor dificultad y ambición especulativa; a saber, “¿qué es el derecho?”. Una teoría del derecho sería posible en la medida que pueda llegar a alcanzar aquello que pretende ser, esto es, exitosa. No obstante lo cual, producto de la decisiva influencia de las observaciones conceptuales de Hart, tal posibilidad ha sido puesta a prueba por las investigaciones meramente semánticas sobre el concepto de derecho.

La tesis central de Raz radica en identificar las condiciones de éxito de una teoría del derecho en la satisfacción de dos criterios; a saber, que (i) la teoría jurídica consista en proposiciones sobre el derecho que sean necesariamente verdaderas y que (ii) tales proposiciones expliquen qué es el derecho. ${ }^{68}$ Esta última condición dice relación con la posibilidad de articular una explicación acerca de la naturaleza del derecho. Dicho objeto es ciertamente distinto e independiente de los estudios abocados a explicar al concepto de derecho. Desde esta óptica, la naturaleza del derecho consiste en un conjunto de elementos o propiedades esenciales y necesarios sin los cuales el derecho no puede ser derecho. ${ }^{69}$ El problema que subyace de esta propuesta radica no solo en los objetivos de una teoría del derecho, sino también en la determinación de una metodología apropiada para alcanzarlos. Si el derecho responde a una entidad ontológica que existe con independencia de cualquier intento de conceptuación, todo tipo de aproximación semántica hacia lo jurídico está incapacitada de cubrirlo epistémicamente. Todos los conceptos consisten en construcciones culturales, desarrollados de manera contingente y situados en contextos particulares. En cambio, el derecho corresponde a aquella tipología de institución social que los agentes denotan en sus prácticas lingüísticas al enunciar al término 'derecho'. ${ }^{70} \mathrm{La}$ naturaleza del derecho existe con prescindencia de las diversas propuestas conceptuales que se formulen, respondiendo a propiedades

${ }^{68}$ RAZ (2004), p. 324.

${ }^{69}$ Ibid, p. 328.

${ }^{70}$ Ibid, p. 331. 
universales y necesarias. De igual modo, la estructura atómica del agua correspondiente a $\mathrm{H}_{2} \mathrm{O}$, se conserva invariablemente en tales términos, aun cuando no se hubiere conceptuado al agua mediante el juicio analítico respectivo según el cual agua es $\mathrm{H}_{2} \mathrm{O}$. Para $\mathrm{Raz}$ tenemos buenas razones para sostener que el derecho no se encuentra desvinculado de este tipo de explicaciones y, de ahí, que la filosofía analítica del derecho haya iniciado un nuevo proceso de reflexiones sobre sí misma.

La fractura entre el análisis conceptual del término 'derecho' y la explicación sobre la naturaleza del derecho, transparenta la tensión existente entre un prisma moderno y premoderno sobre el fenómeno jurídico. El análisis conceptual hartiano constituye una acabada versión moderna sobre lo jurídico, ya que renuncia a estudiar al derecho mediante un concepto clausurado, establecido en virtud de condiciones necesarias y suficientes de aplicación. La aproximación de Hart sobre el derecho lo devela más bien como un conjunto de prácticas sociales y lingüísticas, bajo las cuales el papel central se conjuga por el punto de vista de sus participantes, quienes adoptan un aspecto interno de las reglas, aceptándolas como pautas de comportamiento. ${ }^{71} \mathrm{El}$ sentido de las prácticas jurídicas es definido por quienes participan de ellas. A su vez, la tentativa de predicar propiedades universales y necesarias del derecho, sugiere identificar rasgos inequívocamente premodernos para concebir al derecho. En Hart la contingencia de lo jurídico permite afirmar que únicamente habrá un sistema jurídico maduro o propiamente tal, cuando existan reglas primarias y secundarias, junto a explicaciones no solo versadas desde una perspectiva externa a la práctica jurídica, sino también interna a ella. ${ }^{72}$ Desde Raz, por su parte, existe una multiplicidad de conceptos de derecho que recomiendan el abandono de los estudios semánticos. La versión más robusta de la propuesta hartiana nos habría entregado una alternativa conceptual sobre nuestro concepto de derecho, sin decir nada relevante acerca de qué es el fenómeno jurídico. ${ }^{73}$

La pertinencia epistémica de estas propuestas rivales en teoría jurídica analítica, se debiere resolver en términos de la individuación de lo jurídico. Quizás la adscripción de una de las preguntas relativas a ¿qué es el derecho? y ¿qué es 'derecho'?, parte del supuesto erróneo que se trata de dos empresas totalmente diversas e incompatibles para la reflexión jurídica. No hay que olvidar que el proceso de autocomprensión que inició el Post Scriptum hartiano ya identificaba a su teoría del derecho como una general y descriptiva. De modo que la exigencia de generalidad de su propuesta, entendida como una explicación independiente de cualquier sistema jurídico en particular, frente a la universalidad de las explicaciones que Raz exige para que la teoría del derecho sea posible, pudiere ser una cuestión de grado. Ahora bien, si efectivamente correspondiesen a estrategias incompatibles entre sí, la adjudicación debiere formularse en torno a cuál da cuenta de mejor forma del fenómeno jurídico. En

${ }^{71}$ HART (1963), pp. 99-123.

${ }^{72}$ Ibid, pp. 69-73.

${ }^{73}$ RAZ (2004), p. 331. 
tal sentido, el análisis conceptual y la naturaleza del derecho se ubican en veredas diametralmente distantes. Pensar al derecho desde Raz conlleva rechazar la imagen del derecho como una construcción artificial formulada por la intencionalidad colectiva. La naturaleza del derecho renuncia a la contingencia moderna, reclamando explicaciones sobre un objeto, cuya composición está asociada a elementos universales y necesarios. De igual forma, la transitoriedad y fugacidad de nuestras palabras y conceptos gracias a los cuales refinamos nuestra comprensión de los fenómenos que subyacen tras ellas, se reemplaza por la búsqueda de aquellos elementos que hacen que el derecho sea efectivamente derecho. Su existencia nuevamente se estima necesaria, pues se trata de un derecho dado y no otorgado por los participantes. ${ }^{74}$

Este déficit de intervención en la creación y modificación de los individuos en el fenómeno jurídico, constituye una razón relevante para cuestionar al esquema raziano de teoría del derecho. La operatividad de alguna de estas dos propuestas teóricas descansa en la correcta individuación del derecho en tanto institución social contingente y articulada de manera instrumental mediante un conjunto de prácticas sociales. Identificar a la naturaleza del agua, tigre y oro es bastante distinto a reflexionar en torno al derecho, básicamente porque esa propuesta da cuenta de un yerro fundante en su explicación sobre la naturaleza del derecho; a saber, suponer que el fenómeno jurídico se encuentra expuesto a un examen equivalente al agua, tigre y oro. La institucionalidad del derecho es incompatible con este tipo de análisis. La pregunta ¿qué es el derecho? puede ser adecuadamente analizada a partir del estudio de las palabras y conceptos que utilizamos en nuestras prácticas jurídicas, agudizando nuestra comprensión general sobre el pensamiento jurídico. Después de todo, lo que se encuentra en juego en la discusión es el entendimiento sobre un fenómeno social e institucional complejo y no así de un objeto que necesariamente posea alguna naturaleza, del modo que sostendría toda estrategia monista y premoderna acerca de lo jurídico. ${ }^{75}$

Tales consideraciones dan cuenta de una legítima adjudicación a favor de un esquema moderno, como el hartiano, frente a una aproximación premoderna, tal como la raziana, para comprender al derecho bajo el contexto de la filosofía analítica contemporánea. Sin embargo, no resulta indubitado que prima facie toda

\footnotetext{
74 Desde luego, tanto Hart como Raz suscriben la escisión entre los asuntos del ser y aquellos vinculados al deber ser, aspecto decisivo del positivismo jurídico entendido como una reconstrucción moderna del derecho. Sin embargo, la adscripción de las categorías de moderna y premoderna, a sus respectivas propuestas metodológicas, se justifica ya que a ellas subyacen comprensiones rivales respecto de lo que el derecho es. Si la actividad teórica debe focalizar sus esfuerzos en determinar a la naturaleza de lo jurídico, como lo sugiere Raz, es precisamente porque el derecho posee una naturaleza, conformada por elementos esenciales e invariables. Bajo estas observaciones, nos enfrentamos a un monismo tanto metodológico como conceptual. Metodológico, ya que proclama a una metodología como válida para la teoría analítica del derecho y, a su vez, conceptual, porque reduce el derecho a lo natural o, si se prefiere, procura identificar propiedades naturales en un constructo humano como lo es el fenómeno jurídico.

${ }^{75}$ Una presentación de los planteamientos de Raz, junto a la evaluación crítica de su propuesta metodológica en PEREIRA (2012), pp. 83-104.
} 
versión moderna del fenómeno jurídico, debiere proporcionar una explicación más satisfactoria que una postura premoderna. La distinción entre lo premoderno y moderno del derecho conserva sus rendimientos explicativos en distintas áreas de preocupaciones, pero no se traspasaría necesariamente lo ocurrido en la teoría analítica del derecho a otras parcelas de lo jurídico. Si aquello fuere así, la suerte sufrida por el contraste de perspectivas en el marco de la reflexión estética es distinta a la verificada en los asuntos jurídicos. Si bien en la filosofía analítica del derecho, una explicación moderna sobre el derecho entrega observaciones satisfactorias para decidir a favor de su adopción, en filosofía del derecho privado dicha adjudicación no está exenta de dificultades.

Fernando Atria desarrolló un agudo examen crítico sobre el programa del neoconstitucionalismo, interpretándolo como un esquema premoderno sobre el derecho formulado bajo condiciones modernas. ${ }^{76}$ Buena parte de la actualización del prisma premoderno en los problemas jurídicos ha sido provocada por la significativa influencia de esta corriente, de la cual Dworkin es reconocido como un insigne representante, en las recientes discusiones sobre teoría constitucional. ${ }^{77}$ Para nuestros propósitos, conviene rescatar la evaluación que realiza el autor sobre la conexión entre el neoconstitucionalismo y su condición premoderna.

“[...] ¿por qué es un problema que el neo-constitucionalismo sea premoderno? ¿Hay algo intrínsecamente objetable en una visión premoderna del derecho? La respuesta a esta segunda pregunta puede ser por ahora negativa. El derecho pre-moderno puede no haber sido especialmente inconveniente o arbitrario para tiempos pre-modernos. Pero la pregunta es si hay alguna razón por la que un derecho premoderno sea objetable en nuestras condiciones modernas o postmodernas. ¿Qué puede decirse contra el derecho pre-moderno? La respuesta es: si creemos que nuestro mundo es cuidado y mantenido por la divina providencia, que nuestra sociedad está naturalmente ordenada, y que entre nosotros no existe desacuerdo político que no sea solucionable a través de la argumentación y por referencia a formas aceptadas y dominantes de razonamiento y autoridad moral, de modo que podemos aceptar la pretensión de una elite profesional de jueces y abogados de tener una vía de acceso epistemológicamente privilegiada a la sabiduría práctica que se requiere para decidir los asuntos más fundamentales que nos afectan, nada". ${ }^{78}$

De acuerdo con Atria, la cuestión podría ser disuelta en atención a la razonabilidad de sostener a una comprensión premoderna en un contexto diferenciadamente moderno. La pregunta es si tiene sentido pensar al derecho en términos premodernos en la actualidad, porque pese a que dicho esquema de

${ }^{76}$ ATRIA (2004), pp. 118 y ss.

${ }^{77}$ Esto permite explicar por qué Dworkin tiene una ubicación central en sendas compilaciones dedicadas a la identificación del canon neoconstitucionalista, confirmando la imagen premoderna de su comprensión. Así, véase, DwORKIN (2010), pp. 117-149.

${ }^{78}$ ATRIA (2004), pp. 127-128. 
comprensión fundó una parte considerable del pensamiento occidental, su afirmación sería estéril debido al becho de la modernidad. ${ }^{79}$ Esta visión supone, que en algún sentido, sostener a una concepción acerca del derecho conlleva hacerse cargo del cúmulo de postulados y directrices teórico-políticas que hay detrás de ella. Debido a que existen racionalidades contrapuestas entre ambos prismas, es apropiado organizar al conjunto de consideraciones asociadas a ambas también de un modo dual. No obstante lo cual, hemos visto que existen numerosos problemas para adjudicar idealmente la calificación de premoderna o moderna a una perspectiva sobre el derecho. Asimismo, se ha advertido que no hay una relación de implicación lógica entre los distintos sentidos bajo los cuales una postura sobre el derecho admite ser interpretada como premoderna o moderna. El problema más decisivo es que aun cuando la suscripción de una comprensión premoderna sobre el derecho conllevare la renuncia implícita a los compromisos normativos que justificaron la articulación de la posición moderna, no se sigue de ello que convenga adoptar a esta última si se trata de dar cuenta de una explicación más satisfactoria sobre lo jurídico.

Si el derecho consiste en un complejo de prácticas sociales, el derecho privado presenta un terreno fértil de consideraciones, al momento de evaluar el rendimiento que ahí tendría la distinción entre una comprensión premoderna y otra moderna. En tal sentido, si bien bajo el derecho privado podrían identificarse propuestas en ambas direcciones, no parece resultar indispensable que adoptemos una comprensión moderna para dar cuenta adecuadamente del fenómeno jurídico privado, del modo en que sí ocurría con el análisis conceptual hartiano en la filosofía del derecho. Nuestra conclusión antes expresada en teoría del derecho sobre la adjudicación a favor de una concepción moderna, en desmedro de una premoderna, pudiere sufrir una severa variación cuando tematizamos al sistema jurídico privado. La irreversibilidad estética a lo moderno no es tal en el derecho. En efecto, una postura premoderna en derecho privado puede mostrarse más robusta que otra esgrimida desde un prisma moderno, al implementar el contraste de versiones sobre lo jurídico desarrollado durante este trabajo. Ello explica en parte por qué conviene suscribir con reservas la fractura entre lo premoderno y moderno en los asuntos jurídicos.

De igual manera como sucedía en el seno de la teoría jurídica analítica contemporánea, la teoría del derecho privado se encuentra en un proceso de autocomprensión. Sus esfuerzos están dirigidos a determinar la identidad del derecho privado y los objetivos hacia los cuales debiere este aspirar. ${ }^{80}$ En la actualidad, tales preocupaciones se discuten bajo la lectura de Ernest J. Weinrib y las coordenadas definidas por el análisis económico del derecho, desde la segunda mitad del siglo XX. Mientras la propuesta internalista de Weinrib para entender al derecho privado admite calificarse de premoderna, el esquema de comprensión

${ }^{79}$ En tal sentido, véase HABERMAS (1989), pp. 11-35.

${ }^{80}$ Respecto de la identidad contemporánea de la filosofía del derecho privado, puede consultarse WEINRIB (2012), pp. ix-xx; 1-21; LUCY (2007), pp. 1-44; y ZIPURSKY (2004), pp. 623-632. 
externalista del análisis económico del derecho, corresponde a una lectura moderna sobre el fenómeno jurídico privado. A continuación, revisemos en qué sentidos se despliegan ambas aproximaciones y, enseguida, se procederá a la implementación de nuestro esquema metodológico. En términos polémicos, Weinrib proclamó que "[...] el propósito del derecho privado es ser derecho privado". ${ }^{81}$ Su afirmación buscaba llamar la atención frente a las propuestas surgidas en las distintas variantes del análisis económico del derecho para identificar en objetivos como la eficiencia económica, la supuesta identidad del derecho privado. Estas perspectivas, que el autor denominó genéricamente como instrumentalismos o externalismos, desatendían la dimensión interna y formal de la estructura del sistema jurídico privado, interpretándolo funcionalmente para cumplir propósitos exógenos, que no son los suyos, sino los emanados del mercado.

¿Cómo podría ayudarnos esa afirmación de Weinrib? Si el derecho privado no puede ser nada más que derecho privado, se transparenta una comprensión premoderna sobre tal fenómeno jurídico. El funcionalismo argumenta a favor de la instrumentalidad del derecho privado, entendiendo a sus reglas jurídicas como meros incentivos o desincentivos para alcanzar resultados socialmente deseados. A su vez, un internalismo en el derecho privado rechaza modificar la estructura interna que define la especificidad de las prácticas jurídicas privadas. Mientras el funcionalismo reclama la innovación del derecho privado, sugiriendo que sus postulados se esgriman en atención al futuro y a los cambios surgidos gracias a la repercusión del mercado en el sistema jurídico, el internalismo desafía a la modernidad, privilegiando a la tradición y enfocando sus criterios en las reglas jurídicas que conforman a su imagen definida en el pasado. En estos términos, el análisis económico del derecho supone necesariamente que el derecho privado puede ser algo distinto de lo que ha sido, una versión articulada por la sensibilidad del liberalismo en el fenómeno jurídico. Dicha versión, piensa esta óptica, debiere provocar el abandono de la imagen premoderna esgrimida bajo la postura de Weinrib.

La perspectiva del análisis económico del derecho ha sido calificada como un nuevo paradigma en el derecho civil. ${ }^{82}$ Tal denominación no es gratuita y obedece a la tensión existente entre el paradigma clásico de la reflexión jurídicoprivada que atiende a las reglas como input o insumo que el propio sistema jurídico privado proporciona para su análisis, frente al paradigma moderno relativo a la repercusión de los mercados en el derecho. Este último se expresa en los planteamientos del análisis económico del derecho, que ofrece una dogmática orientada a las decisiones, esto es, a los outputs del sistema jurídico. Ambos modelos responden a cánones contrapuestos de racionalidad. Siguiendo los esquemas sugeridos por Jon Elster, mientras el paradigma clásico de la dogmática privada se interpreta en términos de racionalidad paramétrica, el paradigma

81 WEINRIB (2012), p. 5.

82 PEÑA (1995), p. 327. 
moderno se desenvuelve a la luz de una racionalidad estratégica. ${ }^{83}$ Bajo una racionalidad paramétrica el agente considera que el medio en que se despliega constituye una constante $y$, en tanto, en el contexto de una racionalidad estratégica, el agente estima que su medio interactúa con las expectativas contingentes de los demás. ${ }^{84}$

De acuerdo con Weinrib, el derecho privado debe entenderse como una experiencia peculiar formulada a partir de formas distintivas de interacción entre los particulares. ${ }^{85}$ Por lo tanto, quienes determinan su sentido son quienes participan bajo su marco y prácticas institucionales. La comprensión del fenómeno jurídico se encuentra sujeta a un análisis interno desarrollado desde el reconocimiento de las prácticas del lenguaje y razonamiento empleados bajo el contexto de las relaciones entre particulares. En este sentido, el tipo de interacción que se produce bajo el derecho privado siempre demuestra dimensiones directas de contrariedad o ajustarse a un régimen adversarial. ${ }^{86}$ Aquello ocurre, por ejemplo, si hablamos de contratos en que nuestra experiencia práctica demuestra que concurre un sujeto que ha incumplido sus prestaciones y otro que correlativamente reclama el cumplimiento y la reparación de los perjuicios derivados de la infracción contractual. Además si nos situamos en los derechos reales, existe un dueño a quien cualquier otro le ha privado o perturbado total o parcialmente en su dominio. Finalmente, en el ámbito de la responsabilidad civil extracontractual, se presenta una víctima que ha sido dañada injustamente producto de una interacción espontánea, reclamando la reparación del daño provocado por el agente dañoso.

De modo tal que la estructura del derecho privado es rígida, mostrándose inflexible frente a los insumos proporcionados externamente por el mercado y las expectativas de creación y transferencia de riquezas. El esqueleto bajo el cual se construye el derecho privado está trazado por medio de dos elementos. Uno de carácter institucional y otro de índole conceptual. ${ }^{87}$ Mientras la institucionalidad del fenómeno jurídico privado se expresa mediante mecanismos de adjudicación sobre el conjunto de facultades, derechos y deberes correlativos que le corresponden a los sujetos de una relación jurídica privada, su esfera conceptual alude a la correlatividad característica de la relación privada, porque ahí donde existe una facultad o derecho subjetivo existe un deber o una carga correlativa. Esta estructura interna dota de inteligibilidad al sistema jurídico privado, permitiendo que el sentido de las prácticas de interacción entre demandante y demandado corresponda al significado que para los participantes de las prácticas jurídico-privadas estas posean. Así, el sistema de clausura es coherente, dado que el derecho privado solo puede ser aquello que por su estructura interna está condicionado a ser.

83 ELSTER (1989), pp. 39 y ss.

84 PEÑA (1995), p. 339.

85 WEINRIB (2012), pp. 8-11.

${ }^{86}$ Este énfasis es también compartido en ZIPURSKY (2004), pp. 632-636.

87 WEINRIB (2012), pp. 9-10. 
Si el diagnóstico preliminar sobre la implementación de las dos versiones sobre el fenómeno jurídico fuere acertado, debiéremos adjudicar la disputa en similares términos a lo debatido en la teoría analítica del derecho. De manera que la postura moderna otorgaría una mejor concepción acerca de lo que el derecho es. Sin embargo, aquella solución no se representa en la discusión acerca de la identidad y propósitos del derecho privado. Más bien, la premodernidad formulada en la postura de Weinrib podría estimarse como más satisfactoria para dar cuenta del fenómeno jurídico privado. En efecto, considero que es así. El internalismo y formalismo que presenta Weinrib ofrece genuinas razones para renunciar a la innovación, flexibilidad y rendimientos económicos que promueve una imagen genérica del análisis económico del derecho. Su adopción, en lugar de permitir una explicación más acabada del sistema jurídico privado, podría contribuir a desvirtuarlo. Al interpretar a sus reglas jurídicas como simples incentivos o desincentivos para la realización de comportamientos de agentes racionales, se corre el riesgo de extirpar de toda normatividad al derecho privado. ${ }^{88} \mathrm{El}$ tipo de estructura interna y la relación de interacción directa entre los participantes que identifican a las prácticas jurídico-privadas, llaman a no abandonar a una postura premoderna sobre el fenómeno jurídico privado. En otros términos, si la apuesta por una versión moderna de comprensión de esta esfera de preocupaciones, supone adscribir a su identidad un cálculo estratégico de consecuencias, entonces, el derecho privado no puede sino ser derecho privado.

\section{Consideraciones finales}

Si las anteriores observaciones fueren correctas, conviene tomar con cautela la operatividad de la distinción entre las comprensiones bajo las cuales puede tematizarse al derecho. Ambas perspectivas son, de modo genuino, contrapuestas, ya que suscriben a postulados de identificación que se encuentran en disputa y responden a racionalidades antagónicas. Su pertinencia explicativa es metodológicamente significativa para dar cuenta de los asuntos jurídicos. Ello, porque es muy distinto entender al derecho bajo uno de los dos prismas. No obstante, existen dificultades al momento de aplicar la distinción para calificar a un determinado enfoque como premoderno o moderno. De igual modo, hay una interdependencia entre los distintos postulados y compromisos conceptuales que subyacen a cada perspectiva. Entender a una aproximación bajo alguno de ambos estándares no supone la adscripción de los restantes sentidos en que se presenta la distinción. Aquello confío se haya transparentado mediante la calificación de la propuesta de Ronald Dworkin, como una de carácter premoderna.

Pero el mayor desafío radica en brindar razones de acuerdo a las cuales pudiere concluirse que una comprensión moderna nos provee necesariamente de una versión más robusta que una premoderna, para entender al fenómeno

${ }^{88}$ Una defensa sobre la normatividad del fenómeno jurídico privado en SMITH (2011), pp. 215-242. 
jurídico, del modo en que sí ocurría respecto de los asuntos estéticos. De acuerdo con lo expuesto, los resultados no son análogos según se trate de la teoría jurídica analítica o bien de la teoría del derecho privado contemporáneo. Mientras el análisis conceptual de Hart fortalece a una posición moderna de la jurisprudencia analítica, el internalismo de Weinrib entrega razones para mostrarse escéptico frente a la conveniencia de abandonar una versión premoderna sobre el sistema jurídico privado. Desde luego, podrá considerarse que la presentación del panorama de la reflexión estética constituyó una excusa para mis propósitos. Efectivamente así ocurrió. Pero aún no podemos descartar que el devenir de los estudios sobre la belleza entregue lecciones a la reflexión sobre el derecho. Su advertencia es evidente: la irreversibilidad del contraste en el arte, no tiene por qué traspasarse a las investigaciones acerca del derecho. 
PINTURAS

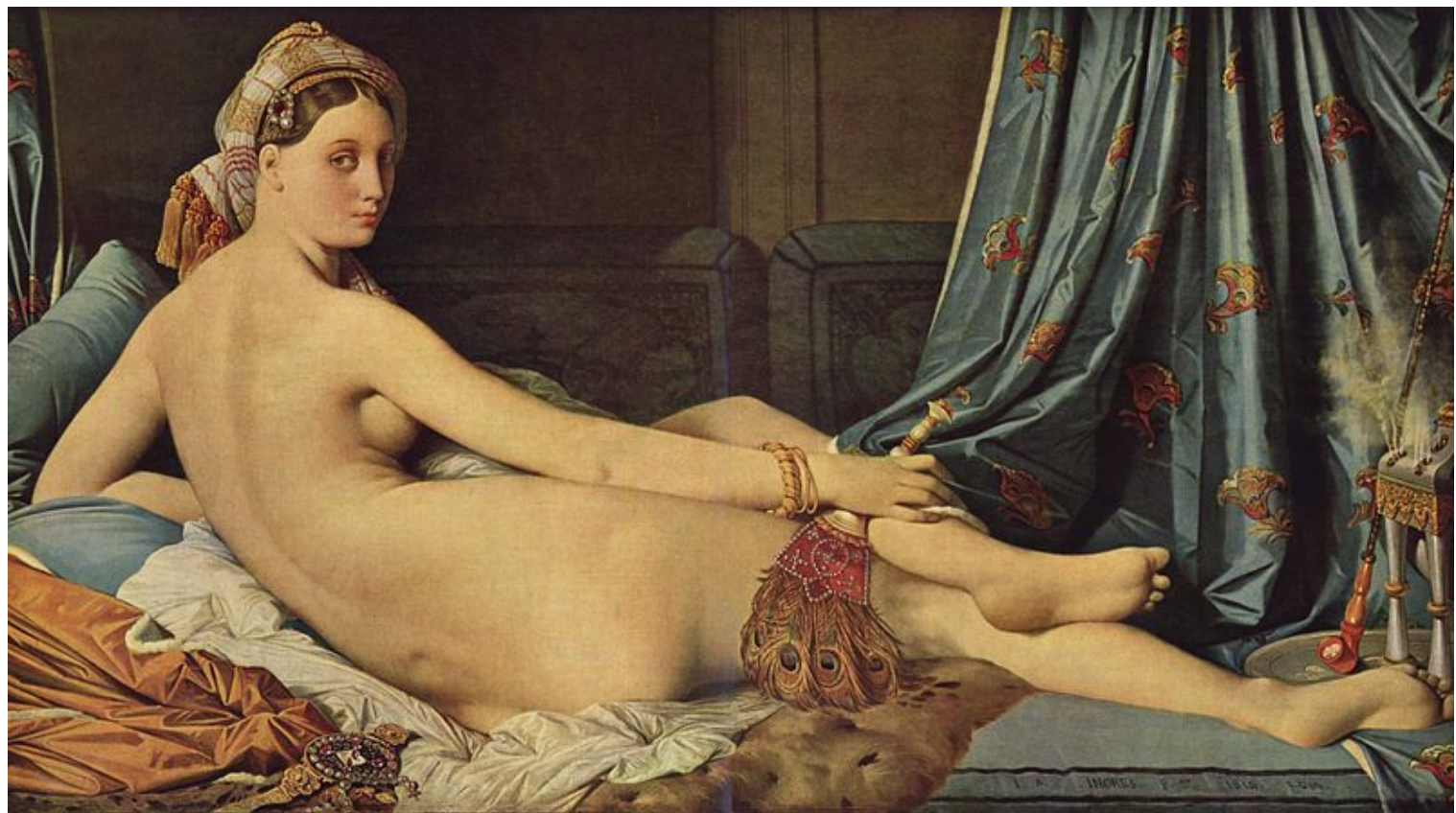

La gran odalisca, Dominique Ingres (1814).

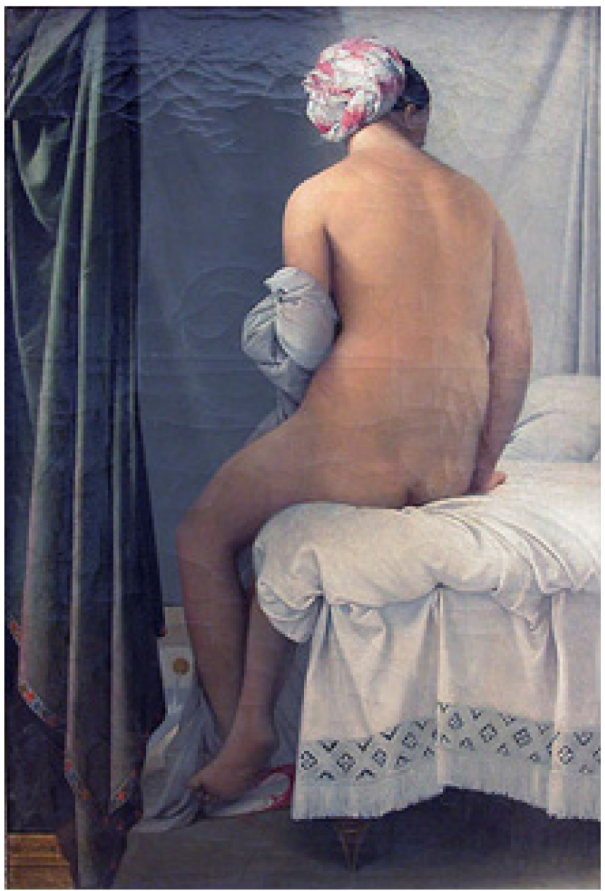

Gran bañista, Dominique Ingres (1808). 


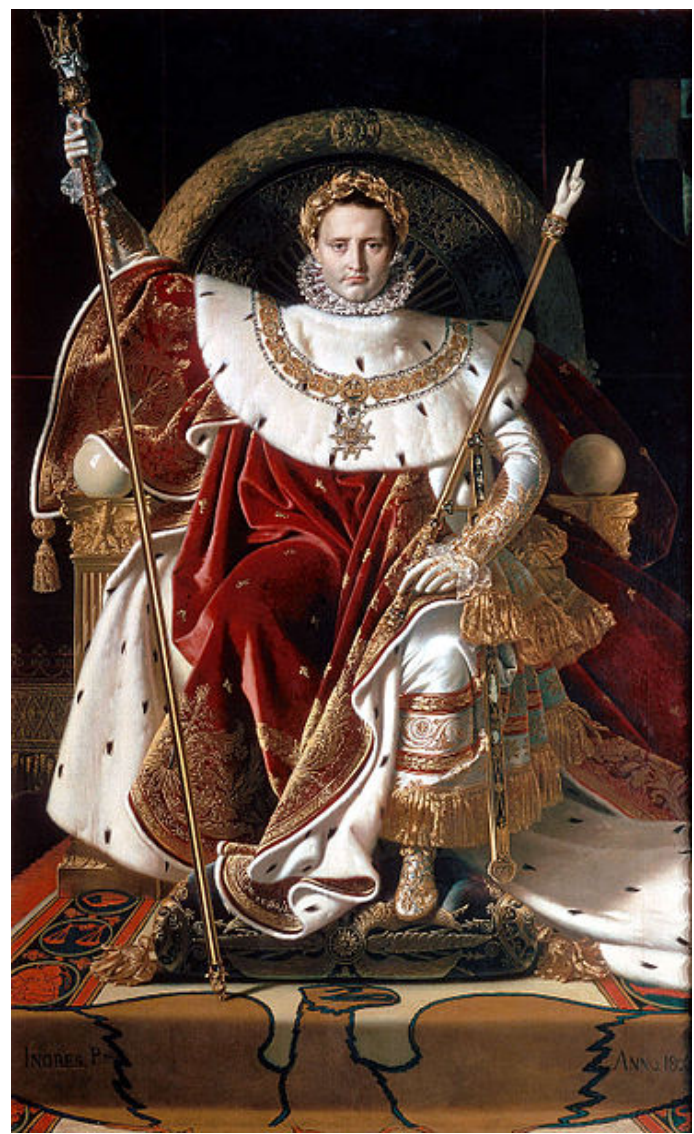

Napoleón en su trono imperial, Dominique Ingres (1806).

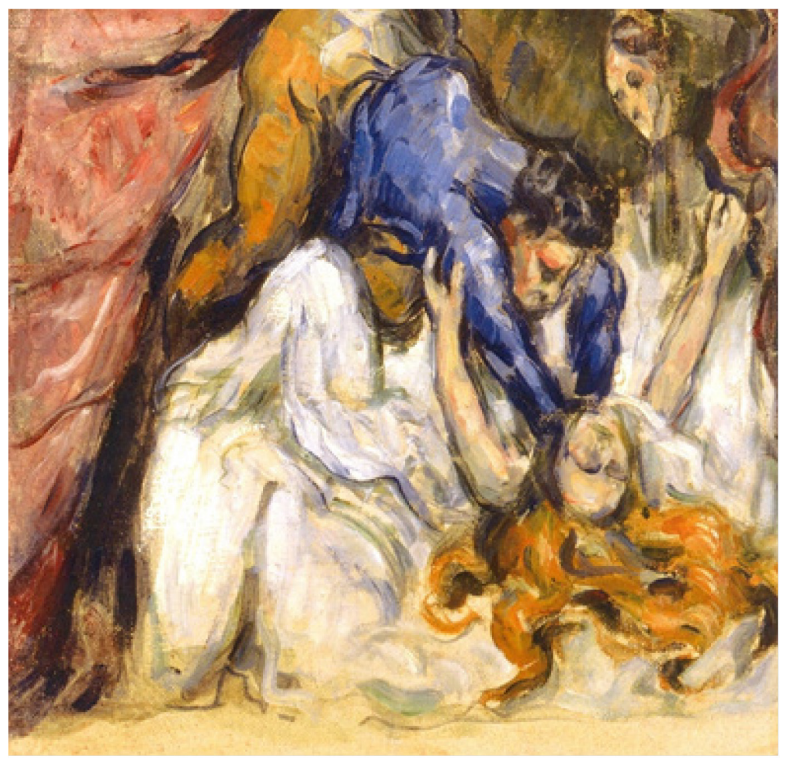

Mujer estrangulada, Paul Cézanne (1870-2). 


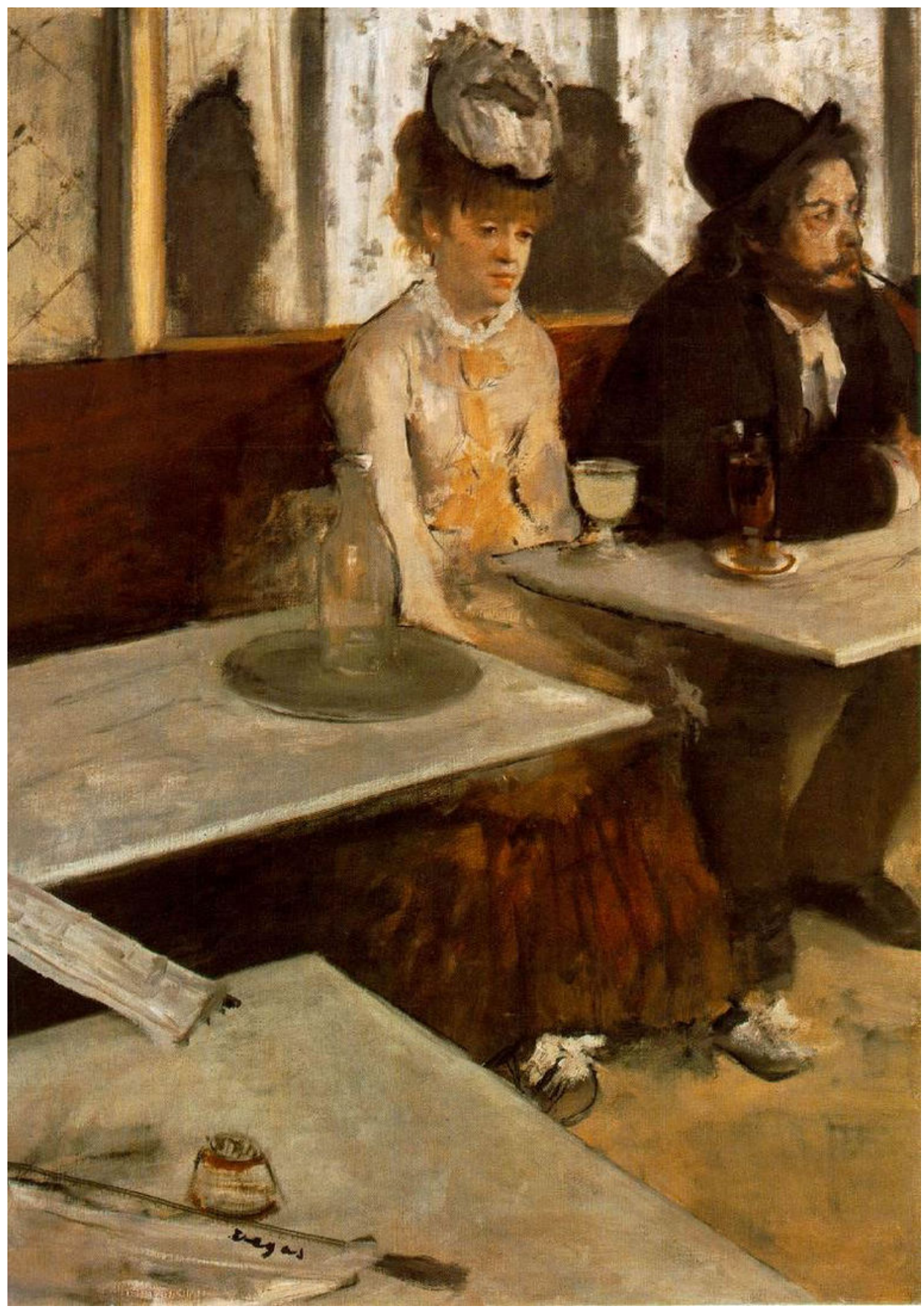

El ajenjo, Edgar Degas (1876). 


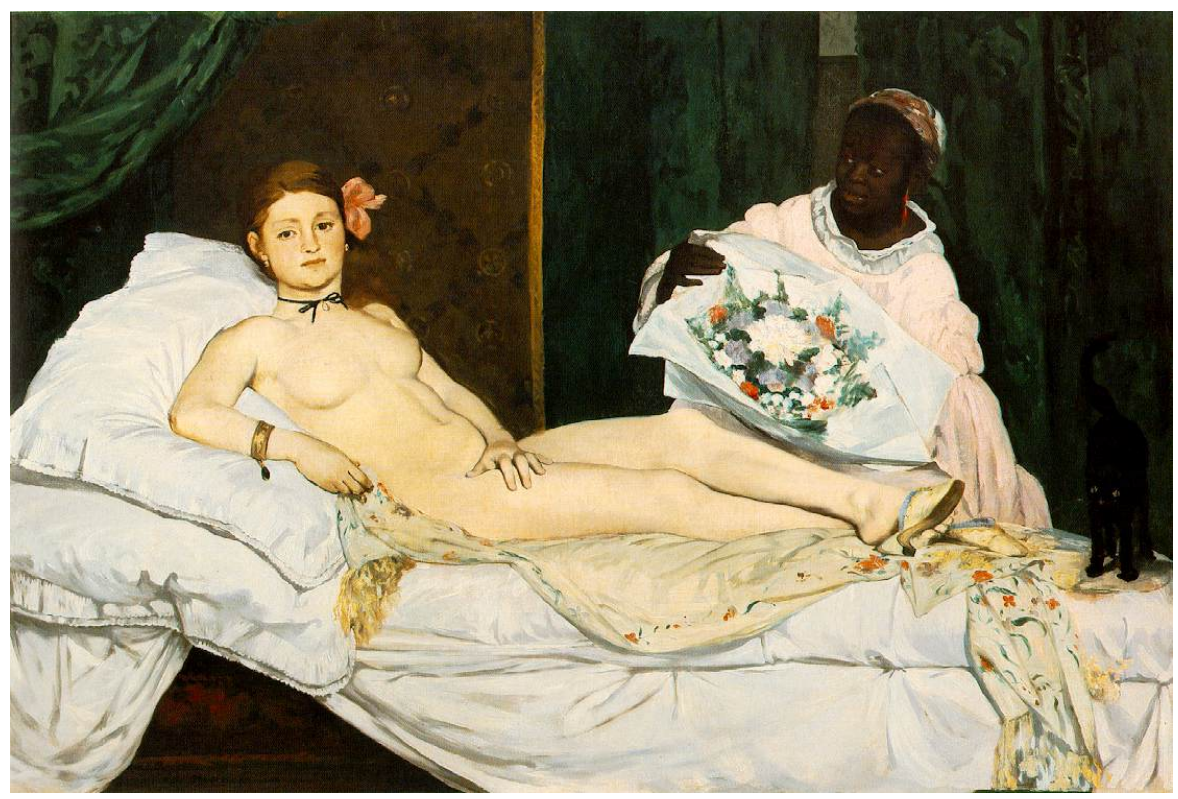

Olympia, Edouard Manet (1863).

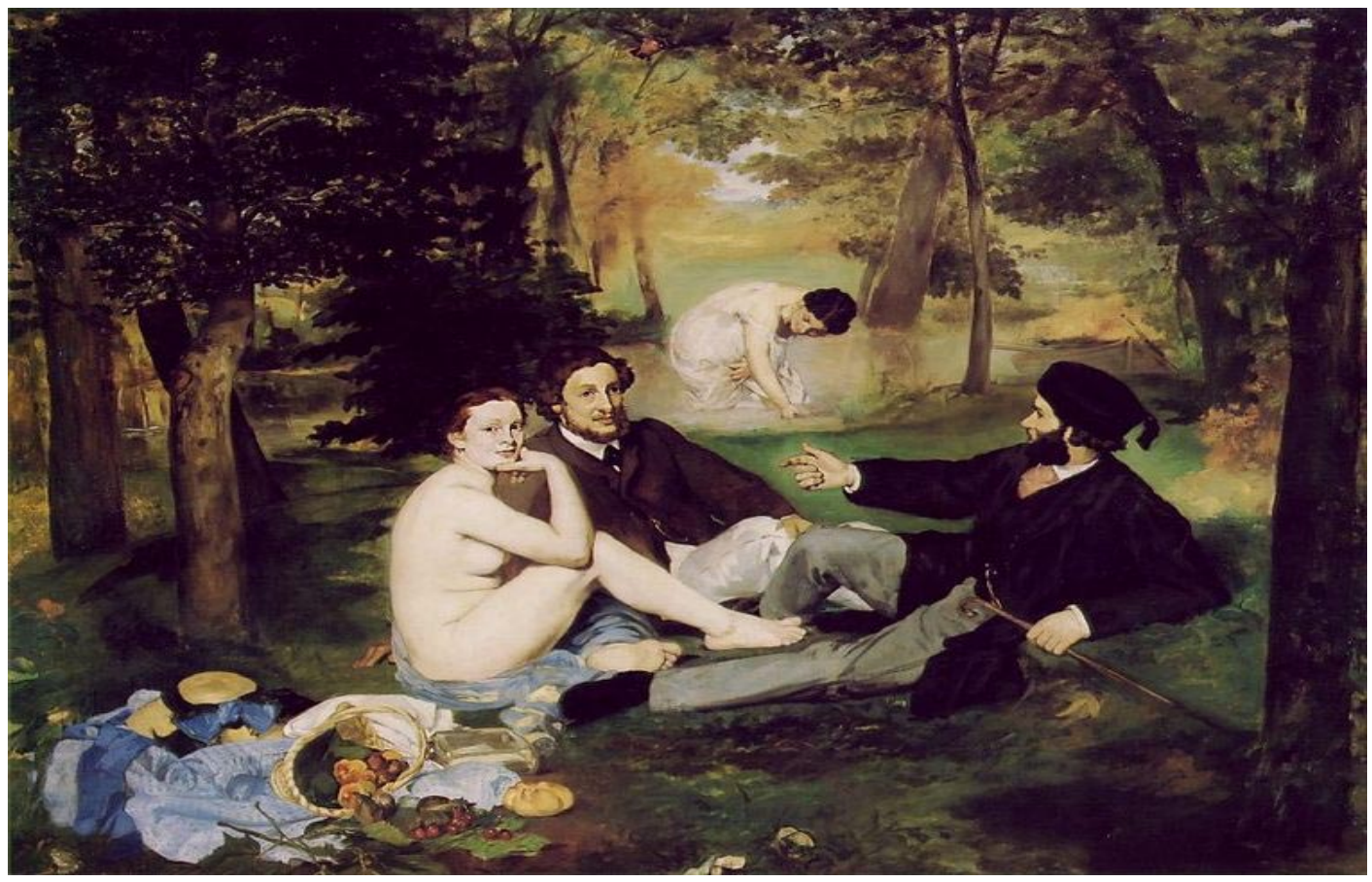

Desayuno sobre la bierba, Edouard Manet (1863). 


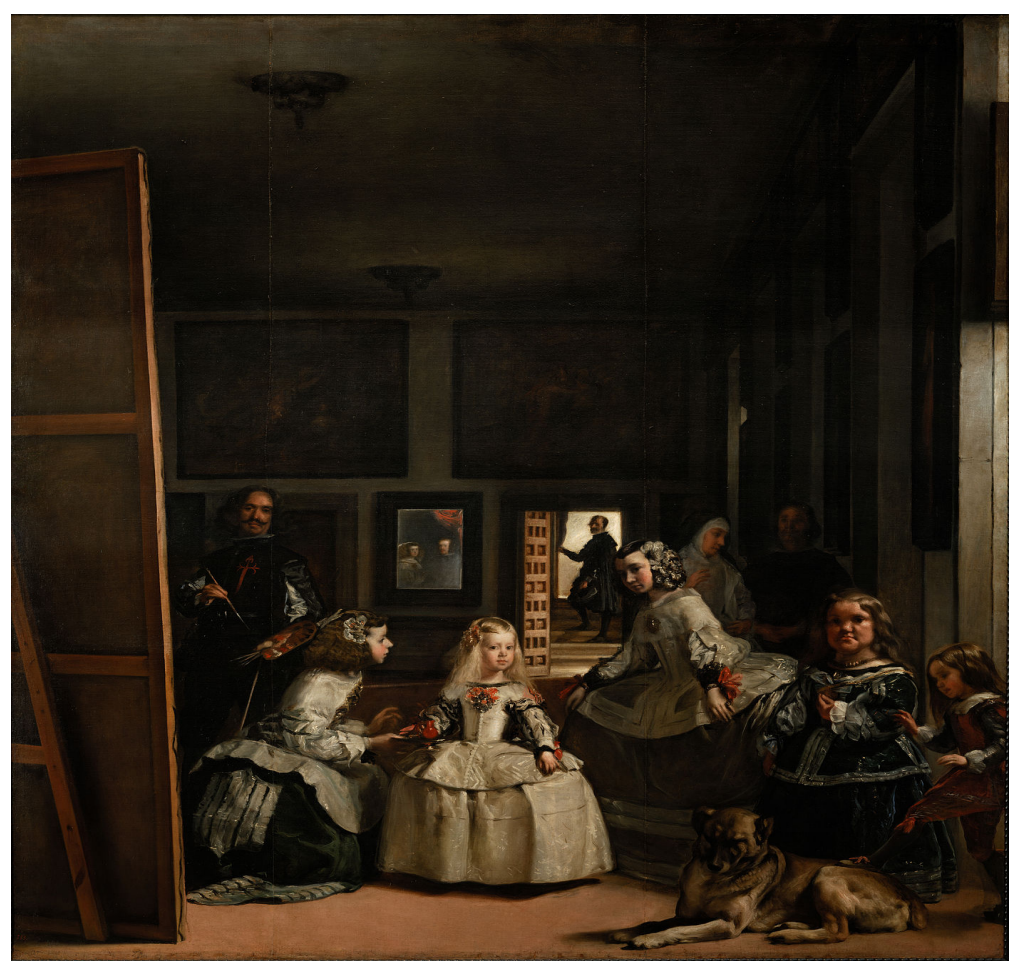

Las Meninas, Diego Velázquez (1656). 
Pereira - Dos versiones sobre el fenómeno jurídico

\section{BIBLIOGRAFÍA}

* Atria, Fernando (2004): "La ironía del positivismo jurídico", en Doxa. Cuadernos de Filosofía del Derecho, No. 27, pp. 81-139.

* Bascuñán Rodríguez, Antonio (1996): “Observaciones sobre la distinción entre derecho natural y derecho positivo en la teoría del derecho de Tomás de Aquino”, en Revista de Ciencias Sociales, No. 41, pp. 301-322.

* Baudelaire, Charles (2005): Salones y otros escritos sobre arte (trad. Carmen Santos). (Madrid: Antonio Machado Libros).

* Detmold, M. J (1989): “Law as practical reason”, en The Cambridge Law Journal, Vol. 48, No. 3, pp. 436-471.

* Dworkin, Ronald (1988): El imperio de la justicia (trad. Claudia Ferrari). (Barcelona, Gedisa). (2010): "Igualdad, democracia y Constitución: Nosotros, el pueblo, en los tribunales” (trad. Alfredo Stolarz), en Miguel Carbonell y Leonardo García Jaramillo (eds.), El canon neoconstitucionalista. (Madrid: Trotta), pp. 117-149.

(1990): "Retorno al Derecho 'natural"” (trad. Santiago Íñiguez de Onzoño), en Jerónimo Betegón y Juan Ramón de Páramo (dir. y coord.), Derecho y Moral: ensayos analíticos. (Barcelona: Ariel) pp. 23-45.

* ELSTER, Jon (1989): Ulises y las sirenas. Estudios sobre racionalidad e irracionalidad (trad. Juan José Utrilla). (México D.F: Fondo de Cultura Económica).

* Foucault, Michel (1997): Las palabras y las cosas. Una arqueología de las ciencias humanas (trad. Elsa Cecilia Frost). (Buenos Aires: Siglo XXI).

* Grossi, Paolo (1996): El orden jurídico medieval (trad. Francisco Tomás y Valiente y Clara Álvarez). (Madrid: Marcial Pons).

(2003): Mitología jurídica de la modernidad (trad. Manuel Martínez Neira). (Madrid: Trotta).

* Habermas, Jürgen. (1989): El discurso filosófico de la modernidad. (Doce lecciones) (trad. Manuel Jiménez Redondo). (Madrid: Taurus).

* HART, H.L.A. (1982): "Commands and authoritative legal reasons", en del mismo Essays on Bentham. Studies in Jurisprudence and Political Theory. (Oxford: Clarendon Press).

(1963): El Concepto de Derecho (trad. Genaro R. Carrió). (Buenos Aires: Abeledo-Perrot).

(1997): "Post Scriptum", en Estudios Públicos, No. 65, pp. 225-263.

* HobBes, Thomas (1992): Leviatán, o la materia, forma y poder de una república eclesiástica y civil (trad. Manuel Sánchez Sarto). (Buenos Aires: Fondo de Cultura Económica).

* Kant, Immanuel (2005): La Metafísica de las Costumbres (trad. Adela Cortina Orts y Jesús Conill Sancho). (Madrid: Tecnos).

* Kelsen, Hans (1986): Teoría Pura del Derecho (trad. Roberto J. Vernengo). (México D.F.: Universidad Nacional Autónoma de México).

* Leiter, Brian (2012): Naturalismo y Teoría del Derecho (trad. Giovanni Battista Ratti). (Barcelona: Marcial Pons).

* LuCy, William (2006): Philosophy of Private Law. (Oxford: Oxford University Press)

* MacCormick, Neil (2011): Instituciones del Derecho (trad. Fernando Atria y Samuel Tschorne). (Madrid: Marcial Pons).

* MacIntyre, Alasdair (2006): Historia de la ética (trad. Roberto Juan Walton). (Barcelona: Paidós).

* PeÑa González, Carlos (1995): "Los desafíos actuales del paradigma del Derecho Civil", en Estudios Públicos, No. 60, pp. 327-348.

* Pereira Fredes, Esteban (2010): "El castigo como problema normativo", en Anuario de Filosofía Jurídica y Social, No. 28, pp. 241-261.

(2012): "La teoría del derecho como posibilidad. Reflexiones en torno a la naturaleza y el concepto de derecho", en Revista de Estudios de la Justicia, No. 17, pp. 83-104. 
(2014): "Tradición analítica de la filosofía del derecho", en Fabiola Vergara Ceballos (ed.), Problemas Actuales de la Filosofía Jurídica. (Santiago de Chile: Librotecnia) pp. 283-322.

* Popper, Karl (2006): La sociedad abierta y sus enemigos (trad. Eduardo Loedel). (Barcelona: Paidós).

* Rawls, John (1974): “Dos conceptos de reglas", en Philippa Foot (ed.), Teorías sobre la Ética (trad. Manuel Arboli). (México D.F.: Fondo de Cultura Económica), pp. 210-247.

* RAZ, Joseph (2004): "Can there be a theory of law?", en Martin Golding y William Edmundson (eds.), The Blackwell Guide to the Philosophy of Law and Legal Theory. (Oxford: Blackwell) pp. 324-342.

(1991): Razón Práctica y Normas (trad. Juan Ruiz Manero). (Madrid: Centro de Estudios Constitucionales).

* Ross, Alf (1970): Sobre el Derecho y la Justicia (trad. Genaro R. Carrió). (Buenos Aires: Eudeba).

* Rousseau, Jean-Jacques (2007): El Contrato Social o Principios de Derecho Político (trad. María José Villaverde). (Madrid: Tecnos).

* Searle, John (1997): La construcción de la realidad social (trad. Antoni Domènech). (Barcelona: Paidós).

* Smith, Stephen A. (2011): "The normativity of private law", en Oxford Journal of Legal Studies, Vol. 31, No. 2, 2011, pp. 215-242.

* Tomás de Aquino (2001): Suma de Teología II, Parte I-II y III, Parte II-II (a) (ed. dirigida por los Regentes de Estudios de las Provincias Dominicanas en España). (Madrid: Biblioteca de Autores Cristianos).

* Weinrib, Ernest J. (2012): The Idea of Private Law. (Oxford: Oxford University Press).

* Wittgenstein, Ludwig (2004): Investigaciones Filosóficas (trad. Alfonso García Suárez y Ulises Moulines). (Barcelona: Crítica).

* Zipursky, Benjamin C. (2004): "Philosophy of private law", en Jules Coleman y Scott Shapiro (eds.), The Oxford Handbook of Jurisprudence \& Philosophy of Law. (Oxford: Oxford University Press) pp. 623-655.

* Zola, Émile (1997): “Édouard Manet. Estudio biográfico y crítico", en Guillermo Solana (ed.), El Impresionismo: la visión original: antología de la crítica de arte (1867-1895). (Madrid: Siruela), pp. 35-109. 